Universidad de Talca - Facultad de Ciencias Jurídicas y Sociales

"La legitimidad en el ejercicio del poder político en el Estado Social de Derecho.

Una revisión desde el caso colombiano"

Carlos Rúa Delgado

\title{
LA LEGITIMIDAD EN EL EJERCICIO DEL PODER POLÍTICO EN EL ESTADO SOCIAL DE DERECHO. UNA REVISIÓN DESDE EL CASO COLOMBIANO*
}

LEGITIMACY IN THE POLITIC POWER

EXERCISE INSIDE SOCIAL STATE UNDERTHE RULE OF LAW. A REVIEW FROM COLOMBIAN CASE

\section{Carlos Rúa Delgado*}

"En las repúblicas, las personas a quienes los sufragios de sus conciudadanos elevan de la masa general

a puestos de gran prominencia y poder, es posible que logren tales recompensas por traicionar su encargo, que, salvo que se trate de espíritus guiados y animados por una virtud superior, parecerá que exceden al interés que pueden tener en el bien común y que predomina sobre las obligaciones del deber".

Alexander Hamilton - "El Federalista"

\section{RESUMEN}

Este texto da cuenta de una comprensión de la manifestación de la legitimidad en el ejercicio del poder político en el Estado Social de Derecho, para lo cual se vale de los conceptos de captura de Estado, clientelismo y corrupción, como hilo conductor para el análisis de cómo se ve afectada la legitimidad política, particularmente la legitimidad material, proponiendo para ello un análisis compartido por la óptica constitucional y por la ciencia política.

ABSTRACT

This text refers to a comprehension about the manifestation of legitimacy in the exercise of politic power in the social state based on the rule of Law, for which uses the concepts of state capture, clientelism and corruption, as axis plot for the analysis

\footnotetext{
* Trabajo recibido el 19 de abril y aprobado el 03 de septiembre de 2013.

Este texto corresponde a un avance del proyecto de investigación denominado "Observatorio por la Transparencia. El Principio de Transparencia en el Estado Social de Derecho", adscrito a la línea de investigación: Transformaciones de la Política y del Derecho en el ámbito de la Gobernabilidad, del Grupo de Investigación Problemas Contemporáneos del Derecho y la Política (GIPCODEP), el cual se encuentra avalado por la Universidad de San Buenaventura Cali (Colombia).

** Abogado de la Universidad Santiago de Cali (Colombia). Magíster en Educación Superior por la Universidad Santiago de Cali (Colombia). Profesor Tiempo Completo Asociado de la Facultad de Derecho de la Universidad de San Buenaventura Cali (Colombia). Correo electrónico: cfrua@usbcali.edu.co.
} 
about the affectation of politic legitimacy, particularly the material legitimacy, proposing for that an shared analysis by constitutional optical as the policy science.

\author{
Palabras Clave \\ Legitimidad, Captura de Estado, Clientelismo, Corrupción \\ KEYWORDS \\ Legitimacy, State capture, Clientelism, Corruption
}

\title{
INTRODUCCIÓN
}

El modelo estatal colombiano escogido por el constituyente de 1991 corresponde al de un Estado Social de Derecho, concepto polisémico que implica un énfasis en lo social por parte del quehacer de la administración pública. Ello quiere decir que la parte orgánica del texto superior sólo adquiere sentido cuando está orientada a la satisfacción de los derechos y principios que aparecen consagrados en la parte dogmática del mismo ${ }^{1}$, en aras de que lo social, precisamente, no se convierta en una "simple muletilla retórica que proporciona un elegante toque de filantropía a la idea tradicional del derecho y del Estado" ${ }^{2}$. Por tal razón, la configuración de los organismos y autoridades que componen la parte orgánica de la Constitución deben gozar de legitimidad en el ejercicio del poder político, no sólo desde un punto de vista formal, a partir del cumplimiento de unos requisitos externos y de alguna manera procedimentales, como lo son las elecciones libres, que buscan la autodeterminación del pueblo en claro acatamiento del principio democrático como soporte fundante del Estado Social de Derecho ${ }^{3}$; sino también, de forma material, en tanto que exista esa

\footnotetext{
${ }^{1}$ Sentencia T-406 de 1992 de la Corte Constitucional de Colombia, M.P. Ciro Angarita Barón.

${ }^{2}$ Esta cita corresponde a la Sentencia T-406 de 1992 de la Corte Constitucional de Colombia, M.P. Ciro Angarita Barón. Sobre este punto también se pueden ver las siguientes sentencias de la misma Corte: Sentencia C-004 de 1992, M.P. Eduardo Cifuentes Muñoz; Sentencia T-598 de 1993, M.P. Eduardo Cifuentes Muñoz; Sentencia T-217 de 1994, M.P. Alejandro Martínez Caballero; Sentencia T-477 de 1995, M.P. Alejandro Martínez Caballero; Sentencia C-048 de 1997, M.P. Hernando Herrera Vergara; Sentencia C-126 de 1998, M.P. Alejandro Martínez Caballero; Sentencia C-595 de 1999, M.P. Carlos Gaviria Díaz; Sentencia C-1037 de 2003, M.P. Jaime Araújo Rentería; Sentencia T-772 de 2003, M.P. Manuel José Cepeda Espinosa; Sentencia T-294 de 2004, M.P. Manuel José Cepeda Espinosa; Sentencia C-864 de 2004, M.P. Jaime Araújo Rentería; Sentencia C-119 de 2006, M.P. Jaime Araújo Rentería; Sentencia C-924 de 2007, M.P. Humberto Antonio Sierra Porto; Sentencia C-1041 de 2007, M.P. Humberto Antonio Sierra Porto; Sentencia T-1094 de 2008, M.P. Clara Inés Vargas Hernández; Sentencia T-018 de 2009, M.P. Jaime Araújo Rentería; Sentencia C -595 de 2010, M.P. Jorge Iván Palacio Palacio; Sentencia C-791 de 2011, M.P. Humberto Antonio Sierra Porto; Sentencia T- 908 de 2012, M.P. Nilson Pinilla Pinilla.

${ }^{3}$ Este aspecto queda aclarado en la Sentencia C-145 de 1994 de la Corte Constitucional de Colombia, M.P. Alejandro Martínez Caballero, la cual señala: "Al consagrar los derechos de participación, conformación, ejercicio y control del poder político, la Constitución de 1991 abandona la idea -propia de las tesis relativas a la soberanía nacional- según la cual los ciudadanos ejercen el voto no como un derecho sino como una función electoral, tal y como lo establecía la Constitución derogada en su
} 
“La legitimidad en el ejercicio del poder político en el Estado Social de Derecho.

relación consecuencial "entre fines y medios expresados en la Constitución" ${ }^{4}$, es decir, que quienes integren, en virtud de un proceso democrático, los órganos del Estado, deben orientar su labor, su actividad administrativa, hacia el cumplimiento de los fines esenciales definidos por la teleología constitucional, lo que implica una relación inescindible entre la función administrativa y los postulados del Estado Social de Derecho ${ }^{5}$.

Esta descripción constitucional se ubica en el plano deontológico, en tanto que expresa un deber ser, cuya búsqueda comprende una constante en el Estado Social de Derecho. Aun así, en muchas ocasiones, esa constante parece desaparecer ante la irrupción de intereses particulares que logran anteponerse al interés general que entraña el cumplimiento de los fines del Estado, razón por la cual, si bien los procedimientos se cumplen, las elecciones se ganan y formalmente se reivindica la legitimidad política a partir de una satisfacción aparente del principio democrático ${ }^{6}$, en la práctica, esa democracia aparece como capturada por

artículo 179. Al ejercer esos derechos, los ciudadanos desarrollan la función electoral por medio de la cual las sociedades democráticas se autoorganizan y se autogobiernan, ya que mediante los procedimientos electorales los ciudadanos conforman y controlan los órganos representativos así como toman de manera directa determinadas decisiones por medio de referendums, consultas y otros mecanismos de democracia participativa. Las funciones electorales son la expresión orgánica del principio democrático. La democracia, desde el punto de vista formal, puede ser definida como un gobierno en el cual los destinatarios de las normas son los mismos que las producen, pues las decisiones colectivas son tomadas por los propios miembros de la comunidad. Esto diferencia el principio democrático de autoorganización de la sociedad -en el cual el orden es construido a partir de la voluntad de los gobernados- del principio autocrático -en el cual son los propios gobernantes quienes determinan el orden social-. Y esa autoorganización de la sociedad se efectúa en lo esencial por medio de los procedimientos electorales". Igualmente en la Sentencia C-566 de 1995 de la Corte Constitucional de Colombia, M.P. Eduardo Cifuentes Muñoz, se reitera la vinculatoriedad entre el Estado Social de Derecho, entendido como principio constitucional, con el principio democrático: "Se torna visible la interdependencia que existe entre el principio del Estado social de derecho y el principio democrático. El primero supone la adopción de políticas sociales que normalmente sólo a través del segundo se establecen. Las demandas por bienes y servicios formuladas por las personas, los grupos, las asociaciones, los partidos y demás formas de acción y cohesión social, se hacen presentes, compiten y se tramitan a través de los distintos mecanismos, directos e indirectos, de participación democrática. La distribución del producto social es esencialmente un asunto político, máxime si entraña gasto público y supone el ejercicio de la potestad tributaria enderezado a arbitrar los recursos para realizarlo".

${ }^{4}$ Rodríguez Ortega, Julio Armando, La Legitimidad en el Estado Social de Derecho, Editorial Leyer, Bogotá D.C., 1998, p. 15.

${ }^{5}$ Ver: Montaña Plata, Alberto, Fundamentos de Derecho Administrativo, Universidad Externado de Colombia, Bogotá D.C., 2010, p. 88.

${ }^{6}$ El principio democrático aparentemente se manifiesta en una única dimensión procedimental que se satisface con los procesos electorales, sin embargo, el principio democrático, como todos los principios constitucionales, no es estático, por el contrario, su configuración dentro del sistema de fuentes del derecho permite que sea dinámico y, por ende, pueda adquirir múltiples dimensiones. Respecto de la multidimensionalidad del principio democrático la Corte Constitucional de Colombia, en Sentencia C-089 de 1994, M.P. Eduardo Cifuentes Muñoz, expresó: "El principio democrático que la Carta prohija es a la vez universal y expansivo. Se dice que es universal en la medida en que compromete variados 
grupos de poder que anteponen sus propios intereses a los del conglomerado, generando, de esta manera, bien una captura, o bien una reconfiguración cooptada del Estado colombiano ${ }^{7}$, lo cual afecta directamente la legitimidad política, ya no desde un punto de vista formal, sino material, en tanto que se desnaturaliza el Estado Social de Derecho, dado que, las instituciones que lo componen no van a aparecer con el sentido de satisfacer los principios y derechos consagrados en la parte dogmática de la Constitución, sino que se van a servir del Estado para los propios intereses de quienes han efectuado la captura de las instituciones. Esta captura se ha dado a través de diversas prácticas, siendo el clientelismo una de las más comunes, práctica que se reproduce simbióticamente con la corrupción, lo cual es objeto de análisis líneas adelante.

Este texto se encuentra escrito en clave de diálogo entre el derecho constitucional y la ciencia política, teniendo al concepto de poder político como telón de fondo de la discusión ${ }^{8}$. El propósito que se busca es la comprensión ${ }^{9}$ de un

escenarios, procesos y lugares tanto públicos como privados y también porque la noción de política que lo sustenta se nutre de todo lo que vitalmente pueda interesar a la persona, a la comunidad y al Estado y sea por tanto susceptible de afectar la distribución, control y asignación del poder social. El principio democrático es expansivo pues su dinámica lejos de ignorar el conflicto social, lo encauza a partir del respeto y constante reivindicación de un mínimo de democracia política y social que, de conformidad con su ideario, ha de ampliarse progresivamente conquistando nuevos ámbitos y profundizando permanentemente su vigencia, lo que demanda por parte de los principales actores públicos y privados un denodado esfuerzo para su efectiva construcción. La interpretación constitucional encuentra en el principio democrático una pauta inapreciable para resolver dudas o colmar lagunas que puedan surgir al examinar o aplicar un precepto. En efecto, a la luz de la Constitución la interpretación que ha de privar será siempre la que realice más cabalmente el principio democrático, ya sea exigiendo el respeto a un mínimo de democracia o bien extendiendo su imperio a un nuevo ámbito".

7 Los conceptos de captura de Estado y reconfiguración cooptada de Estado son desarrollados por Garay, Luis Jorge; Salcedo-Albarán, Eduardo, De León-Beltrán, Isaac y Guerrero, Bernardo, La captura y reconfiguración cooptada del Estado colombiano, Fundación Método-Fundación Avina-Transparencia por Colombia, Bogotá D.C., 2008.

8 "Lo que parece evidente es que, como denominador común a Derecho Constitucional y Ciencia Política, se encuentra el problema básico del uso del poder. Su ejercicio legítimo, a través de las instituciones libremente establecidas y elegidas; su ejercicio meramente legal, siguiendo los procedimientos prescritos, pero no siempre en base a un apoyo popular que los respalde; y su ejercicio al margen de la legalidad y/o de la legitimidad, son sin duda el objeto mismo, el denominador común de la Ciencia Política y el Derecho Constitucional". Cazorla Pérez, José, Manual de Introducción a la Ciencia Política, Fundación Núcleo de Esco, Granada, 2008, pp. 25-26. En: http://dspace.utalca.cl/ bitstream/1950/9174/1/Texto_Completo.pdf [visitado el 02/08/2013].

${ }^{9}$ La comprensión enunciada se entiende en el sentido de apropiación, tal y como aparece en el pensamiento de Gadamer: "El que 'comprende' un texto (o incluso una ley) no sólo se proyecta a sí mismo, comprendiendo, por referencia a un sentido -en el esfuerzo del comprender- sino que la comprensión lograda representa un nuevo estadio de libertad espiritual. Implica la posibilidad de interpretar, detectar relaciones, extraer conclusiones en todas las direcciones, que es lo que constituye al 'desenvolverse con conocimiento' dentro del terreno de la comprensión de los textos. Y esto vale también para el que se desenvuelve adecuadamente con una máquina, esto es, el que entiende su funcionamiento, o el que se maneja concretamente con una herramienta: supuesto que la comprensión basada en la 
fenómeno: cómo se manifiesta la legitimidad en el ejercicio del poder político en el marco del modelo estatal denominado Estado Social de Derecho, a partir de la revisión del caso colombiano. La comprensión de dicho fenómeno implica un posicionamiento en la hermenéutica ${ }^{10}$, dada la implicación en la apropiación de la historia, lo que denota una ubicación metodológica dentro del paradigma cualitativo $^{11}$ de la investigación en ciencias sociales ${ }^{12}$. El diálogo de saberes

racionalidad de la relación entre medios y fines está sujeta a una normativa distinta de la que preside la comprensión de expresiones vitales y de textos, lo que es verdad es que en último extremo toda comprensión es comprenderse. También la comprensión de expresiones se refiere en definitiva no sólo a la captación inmediata de lo que contiene la expresión, sino también al descubrimiento de la interioridad oculta que la comprensión permite realizar, de manera que finalmente se llega a conocer también lo oculto. Pero esto significa que uno se entiende con ello. En este sentido vale para todos los casos que el que comprende se comprende, se proyecta a sí mismo hacia posibilidades de sí mismo". GADAMER, Hans-Georg, Verdad y Método, decimosegunda edición, Ediciones Sígueme, Salamanca, 2007, pp. 325-326.

${ }^{10}$ En principio, podría decirse que la hermenéutica implica el estudio del acto comprensivo, aunque también se emplea como método para orientar la interpretación o la comprensión de un asunto determinado, fenómeno, texto, relato, conocimiento histórico, etc. La hermenéutica aparece entonces como método, en la medida en que se convierte en un camino de apropiación del objeto de conocimiento. Gianni Vattimo indica que la hermenéutica es la nueva koiné de la filosofía, como quiera que se trata del "lenguaje común" de los trabajos filosóficos contemporáneos, situación que se presenta desde la aparición de la obra de Gadamer, a principios de la segunda mitad del siglo XX, aunque acentuada desde la década de 1980, como reemplazo de otras "lenguas comunes" de la filosofía que imperaron en décadas anteriores: marxismo y estructuralismo, por ejemplo. En el derecho, la hermenéutica ofrece un campo en donde la comprensión del texto legal, por ejemplo, no obedece únicamente a parámetros lingüísticos ni a reglas de aplicación legislativa, sino que exige un diálogo con los sujetos, con la historia y con todos los elementos que entran en tensión en el campo. La hermenéutica es un ejercicio del pensamiento que busca llegar a una verdadera comprensión de la historia, los fenómenos, los textos, los relatos o, incluso, las leyes. Arráez, Calles y Moreno de Tovar, parafraseando a Paul Ricoeur, la definen como sigue: "De esta manera, entendemos la Hermenéutica como una actividad de reflexión, en el sentido etimológico del término, es decir, una actividad interpretativa que permite la captación plena del sentido de los textos en los diferentes contextos por los que ha atravesado la humanidad. Interpretar una obra es descubrir el mundo al que ella se refiere en virtud de su disposición, de su género y de su estilo". ArRÁez, Morella, Calles, Josefina y Moreno de Tovar, Liuval, "La Hermenéutica: una actividad interpretativa", Revista Sapiens, vol. 7, № 2, diciembre, Universidad Pedagógica Experimental Libertador, Caracas, 2006, p. 174. En: http://www.redalyc.org/articulo.oa?id=41070212 [visitado el 02/08/2013].

11 "El enfoque cualitativo también se guía por áreas o temas significativos de investigación. Sin embargo, en lugar de que la claridad sobre las preguntas de investigación e hipótesis preceda a la recolección y el análisis de los datos (como en la mayoría de los estudios cuantitativos), los estudios cualitativos pueden desarrollar preguntas e hipótesis antes, durante o después de la recolección y el análisis de los datos. Con frecuencia, estas actividades sirven, primero, para descubrir cuáles son las preguntas de investigación más importantes, y después, para refinarlas y responderlas. La acción indagatoria se mueve de manera dinámica en ambos sentidos: entre los hechos y su interpretación, y resulta un proceso más bien 'circular' y no siempre la secuencia es la misma, varía de acuerdo con cada estudio en particular". Hernández Sampierı, Roberto; Fernández Collado, Carlos y Baptista Lucio, María del Pilar, Metodología de la Investigación, quinta edición, McGraw-Hill, México, 2010, p. 7.

${ }^{12}$ Entre la hermenéutica y la investigación cualitativa existe una relación intrínseca, tanto que autores como Sandoval Casilimas ubican a la primera como una expresión metodológica de la segunda: "Esta 
pretendido entre derecho y ciencia política es un diálogo entre dos ciencias sociales que trabajan conceptos aparejados desde diversas ópticas, como los conceptos de Estado, poder y legitimidad, que son transversales al desarrollo de las ideas aquí propuestas. Como se enunció líneas atrás, las descripciones constitucionales del Estado Social de Derecho en cuanto al rol de la teleología constitucional como orientadora de la actividad administrativa se ubican en el plano deontológico, en cuanto entrañan un deber ser, lo cual conlleva un doble análisis a partir del diálogo de saberes propuesto: por una parte, desde la dogmática constitucional, el Estado Social de Derecho ostenta la doble condición de principio constitucional ${ }^{13}$ y de cláusula general superior ${ }^{14}$, lo que reafirma su carácter deontológico ${ }^{15} y$, por la otra, desde la ciencia política, ese deber ser

alternativa de investigación cualitativa, aparece como una opción que no se agota exclusivamente en su dimensión filosófica sino que trasciende a una propuesta metodológica en la cual la comprensión de la realidad social se asume bajo la metáfora de un texto, el cual es susceptible de ser interpretado mediante el empleo de caminos metodológicos con particularidades muy propias que la hacen distinta a otras alternativas de investigación". SANDOval CASILIMAS, Carlos, Investigación Cualitativa, ICFES, Bogotá D.C., 1996, p. 67.

13 "Los principios Constitucionales, a diferencia de los valores que establecen fines, consagran prescripciones jurídicas generales que suponen una delimitación política y axiológica reconocida y, en consecuencia, restringen el espacio de interpretación, lo cual hace de ellos normas de aplicación inmediata, tanto por el legislador como por el juez constitucional. Son principios constitucionales, entre otros, los consagrados en los artículos primero y tercero: el Estado social de derecho, la forma de organización política y territorial, la democracia participativa y pluralista, el respeto de la dignidad humana, el trabajo, la solidaridad, la prevalencia del interés general (artículo 1); la soberanía popular y la supremacía de la Constitución (artículo 2). Ellos se refieren a la naturaleza política y organizativa del Estado y de las relaciones entre los gobernantes y los gobernados. Su alcance normativo no consiste en la enunciación de ideales que deben guiar los destinos institucionales y sociales con el objeto de que algún día se llegue a ellos; su valor normativo debe ser entendido de tal manera que signifiquen una definición en el presente, una base axiológico-jurídica sin la cual cambiaría la naturaleza misma de la Constitución y por lo tanto toda la parte organizativa perdería su significado y su razón de ser". Sentencia T-406 de 1992, M.P. Ciro Angarita Barón, de la Corte Constitucional de Colombia.

14 "La cláusula del Estado social de derecho tiene el poder jurídico de movilizar a los órganos públicos en el sentido de concretar, en cada momento histórico, un modo de vida público y comunitario que ofrezca a las personas las condiciones materiales adecuadas para gozar de una igual libertad. No puede pretenderse, que de la cláusula del Estado social surjan directamente derechos a prestaciones concretas a cargo del Estado, lo mismo que las obligaciones correlativas a éstos. La individualización de los derechos sociales, económicos y culturales, no puede hacerse al margen de la ley y de las posibilidades financieras del Estado. El legislador está sujeto a la obligación de ejecutar el mandato social de la Constitución, para lo cual debe crear instituciones, procedimientos y destinar prioritariamente a su concreción material los recursos del erario". Sentencia SU-111 de 1997, M.P. Eduardo Cifuentes Muñoz, de la Corte Constitucional de Colombia.

${ }^{15}$ Sobre este punto revisar la Sentencia C-1514 de 2000, M.P. Martha Victoria Sáchica Méndez, que reafirma la ubicación de los principios constitucionales en un plano deontológico: "Los principios constitucionales, por su parte, están ubicados en el plano deontológico. La estructura propia de estas normas -contienen prescripciones jurídicas-, permite al juez, a través de una metodología eminentemente jurídica, que "descubra" las reglas jurídico-constitucionales contenidas en el principio; ello no impide, en todo caso, al legislador su desarrollo, en virtud del principio democrático". 
implica la adopción de un enfoque político normativo ${ }^{16}$, dado el acento en el deber ser de la política ${ }^{17}$, no como especulación moralista, sino como cuestión orientadora en la apropiación de los conceptos y de la historia, en tanto que se entiende a ésta como orden y consenso ${ }^{18}$.

\section{Aproximación al CONCEPTO DE LeGitimidad \\ POLÍTICA Y SU RELACIÓN CON EL EJERCICIO DEL PODER EN EL ESTADO}

El devenir conceptual de la legitimidad política aparece como representación justificatoria del poder político, bien sea como concreción de un consenso a partir de un proceso electoral ${ }^{19} \mathrm{O}$ como necesidad, en términos de funcionalidad del poder $^{20}$. La legitimidad contiene el reconocimiento del ejercicio del poder político por parte del Ilamado a ejercerlo, no de otro, es decir, de quien ostenta la titularidad del poder político, dado que esa titularidad aparece como consecuencia de la asunción al cargo que demanda el ejercicio del poder político y de la correspondiente aceptación del mismo por parte de los asociados al Estado ${ }^{21}$.

\footnotetext{
${ }^{16}$ Ver: Harto De Vera, Fernando, Ciencia Política y Teoría Política contemporáneas: una relación problemática, Trotta, Madrid, 2005, pp. 177-178.

${ }^{17}$ Ver: Arnoletto, Eduardo Jorge, Curso de Teoría Política, edición electrónica gratuita, 2007, p. 28. En: www.eumed.net/libros/2007b/300/ [visitado el 26/12/2012].
}

18 "El primero que entiende la política como orden y consenso corresponde al modelo normativo (en cuanto modelo es posible llenarlo de contenidos diferentes) que parte de una situación no política, de una situación prepolítica a la sociedad política y termina con la instauración del estado mediante el pacto producto de la voluntad racional. Este modelo va desde Hobbes hasta Habermas pasando por Rawls. El modelo normativo contrapone el estado no político (estado natural) al estado político (nonatural)." Ortega, Onasis, "Dos caras de la filosofía política contemporánea", Revista Praxis Filosófica, Nueva serie, № 25, julio-diciembre, Universidad del Valle, Cali, 2007, p. 113.

${ }^{19} \mathrm{Al}$ respecto el iusfilósofo Norberto Bobbio ilustra: "Ahora bien, en el juego político democrático -donde se entiende justamente por sistema democrático un sistema cuya legitimidad depende del consenso que se verifica periódicamente por medio de elecciones libres por sufragio universal- los actores principales son los partidos (en nuestro sistema estipulados constitucionalmente en el artículo 49) y la manera principal de hacer política para la inmensa mayoría de los miembros de la comunidad nacional son las elecciones". Bоввıо, Norberto, El futuro de la democracia, Fondo de Cultura Económica, México, 1986, p. 53.

${ }^{20}$ Ver: ScharpF, Fritz, "Conceptos de legitimación más allá del Estado-nación", Revista Española de Ciencia Política, № 13, octubre, Asociación Española de Ciencia Política y de la Administración, Madrid, 2005, p. 15.

21 "La legitimidad es el reconocimiento por parte de la población de que los gobernantes de su Estado son los verdaderos titulares del poder y los que tienen derecho a ejercerlo: a crear y aplicar normas jurídicas, disponiendo del monopolio de la fuerza, de acuerdo con esas normas, sobre la población". LóPEZ HeRnÁnDEZ, José, "El concepto de legitimidad en perspectiva histórica", Cuadernos Electrónicos de Filosofía del Derecho, № 18, Instituto de Derechos Humanos de la Universidad de Valencia, Valencia, 2009, p. 156. En: http://ojs.uv.es/index.php/CEFD/article/view/ 116/124 [visitado el 18/11/2012]. 
El concepto de legitimidad aparece, pues, ceñido al de poder político, en tanto que se representa como justificación de su ejercicio ${ }^{22}$. En términos de Bertrand Russell ${ }^{23}$, el poder aparece como un concepto cuantitativo que se puede definir como la producción de los efectos pretendidos. No se puede hablar de legitimidad sin hablar de poder, ni se puede hablar de poder sin hablar de política, dado que la política se define a sí misma a partir del ejercicio del poder $^{24}$, por ello la legitimidad suele presentarse con un carácter justificatorio, verbigracia, en Guglielmo Ferrero ${ }^{25}$, para quien ésta aparece como una necesidad de justificación del poder político, el cual va ligado, también, al concepto de dominación, entendiendo por éste el derecho de unos hombres de mandar sobre otros hombres. Para el autor la legitimidad aparece como necesidad, dado que "entre todas las desigualdades humanas, ninguna es tan importante por sus consecuencias ni tiene tanta necesidad de justificarse ante la razón, como la establecida por el poder ${ }^{\prime 26}$. Por tal motivo este autor encuentra cuatro principios de lo que él denomina principios de legitimidad como justificaciones del poder, los cuales se han ido entremezclando en la historia. Esos principios son el electivo, el democrático, el aristocrático-monárquico y el hereditario ${ }^{27}$. En el pensamiento de Ferrero, "los principios de legitimidad no son más que ensayos de justificación del poder, explicaciones que pretenden fundamentar el derecho del gobernante a mandar y el deber de los gobernados a obedecer ${ }^{\prime \prime 2}$. Es así como Ferrero ${ }^{29}$ considera que el ejercicio del poder en las democracias

\footnotetext{
22 Rodríguez Ortega, La Legitimidad, cit. nota n. 4, p. 20.

${ }^{23}$ Russel, Bertrand, Power. A New Social Analysis, first edition, sixth impression, George Allen \& Unwin, London, 1948, p. 35.

24 "La política hace referencia a aquellos fenómenos que afectan a una sociedad en su conjunto y que tienen que ver con la organización y dirección de la misma mediante el uso de la fuerza. Estas tres características, organización, dirección y uso de la fuerza en una sociedad, definen el hecho del poder político". López HeRnÁNDEZ, "El concepto", cit. nota n. 21, p. 154.

${ }^{25}$ Ferrero, Guglielmo, El Poder. Los genios invisibles de la ciudad, Editora Inter-Americana, Buenos Aires, 1943.

${ }^{26}$ Ferrero, Guglielmo, El Poder, cit. nota n. 25, p. 35.

${ }^{27}$ El principio electivo y el principio democrático tienen que ver con el acceso al poder por medio de unas elecciones o a través de procedimientos democráticos. Las democracias contemporáneas, según Ferrero, corresponden a una combinación entre estos dos principios de legitimidad. A su vez, los principios monárquico y hereditario tienen que ver con el acceso al poder por medio de la sangre o de la pertenencia a un grupo social determinado. Para Ferrero estos también se combinaron en Europa durante la época del absolutismo monárquico y supone la superioridad de una familia o de un grupo de familias.

${ }^{28}$ Martínez Ferro, Hernán, "Los principios de la legitimidad política (Ferrero y los genios invisibles de la ciudad)", Revista Diálogos de Saberes, № 31, julio-diciembre, Universidad Libre de Colombia, Bogotá D.C., 2009, p. 204.

${ }^{29}$ Ferrero, El Poder, cit. nota n. 25, pp. 33-34.
} 
modernas se justifica sobre dos principios de legitimidad mezclados: el democrático y el electivo, en tanto que el primero se refiere al reconocimiento de la soberanía popular y el segundo se funda sobre las elecciones libres de los representantes del pueblo.

Esa relación entre soberanía y legitimidad también aparece en Kriele, para quien "la soberanía del Estado depende de su legitimidad, y la legitimidad fundamenta su soberanía"30. Más aún, podría decirse que "el problema de la legitimidad es el lado interno del problema de la soberanía" ${ }^{\prime 31}$. El mismo López Hernández, líneas abajo, es claro en señalar: "por tanto, la soberanía y la legitimidad son las propiedades esenciales del poder político estatal. Pero la legitimidad se refiere sobre todo a la cuestión interna del título y ejercicio del poder" ${ }^{\prime \prime 2}$.

La relación legitimidad-poder sobre el fondo de la dominación, encuentra en Max Weber ${ }^{33}$ uno de sus autores más importantes. Para Weber la legitimidad corresponde a una creencia de los dominados en hacerse sumisos a la autoridad, lo cual asegura la capacidad de ésta para hacer cumplir sus decisiones. En Weber el concepto de dominación corresponde a "la probabilidad de encontrar obediencia dentro de un grupo determinado para mandatos específicos (o para toda clase de mandatos) $)^{\prime 34}$. Este autor identifica tres tipos de dominación legítima ${ }^{35}:$ a) dominación de carácter racional, que se refiere a la creencia en la legalidad del orden estatuido y del derecho de mando de las autoridades por virtud de la legalidad (dominación burocrática); b) dominación de carácter tradicional, que corresponde a la creencia de la santidad de las tradiciones y de los señalados por esas tradiciones para ejercer autoridad (dominación patriarcal), y c) dominación de carácter carismática, que se refiere a la creencia en la santidad, heroísmo o ejemplaridad de una persona para ejercer autoridad (dominación caudillista, profética o demagógica). De estos tipos de dominación surgen sus correspondientes creencias de legitimidad, las cuales deben asegurar el mantenimiento de las relaciones de dominación-sumisión, dado que los motivos estrictamente materiales, afectivos o racionales no pueden garantizar por sí mismos el mantenimiento de la dominación, si ésta no se representa como una creencia del dominado.

\footnotetext{
${ }^{30}$ Kriele, Martin, Introducción a la Teoría del Estado, Buenos Aires, Depalma, 1980, p. 13.

31 López Hernández, "El concepto", cit. nota n. 21, p. 156.

32 López Hernández, "El concepto", cit. nota n. 21, p. 156.

33 Weber, Max, Economía y Sociedad I, segunda edición, segunda reimpresión, Fondo de Cultura Económica, México, 1974, pp. 170-173.

34 Weber, Max, Economía y Sociedad I, cit. nota n. 33, p. 170.

${ }^{35}$ Weber, Max, Economía y Sociedad I, cit. nota n. 33, p. 172.
} 
El estudio weberiano del poder y la legitimidad que deviene tiene en uno de sus propósitos fundamentales el establecer cuándo un poder es legítimo, en tanto que puede darse que la dominación dependa de otros motivos diferentes, como el juego de intereses particulares, o del hábito de sumisión o del puro gusto personal del súbdito, motivos que en todo caso hacen que la relación de dominación resulte inestable. Por ello, Weber expresa que la motivación más estable y legítima es la que se funda en motivos jurídicos. Es así como señala al respecto: "En las relaciones entre dominantes y dominados, en cambio, la dominación suele apoyarse internamente en motivos jurídicos, en motivos de su 'legitimidad', de tal manera que la conmoción de esa creencia en la legitimidad suele, por lo regular, acarrear graves consecuencias" ${ }^{\prime 36}$.

La legitimidad weberiana está basada en la legalidad iuspositiva del momento, esto es, la preponderancia del derecho positivo como uno de los factores estructurales del Estado moderno, situación que es criticada duramente por Habermas $^{37}$, quien considera que Weber no supo reconocer el ingrediente moral que pervive en las entrañas del derecho que proviene de los Estados liberales, dada la positivización de muchas normas morales. Según Habermas el derecho moderno está estructurado sobre reglas y principios, muchos de los cuales ostentan la doble naturaleza jurídica y moral ${ }^{38}$.

\footnotetext{
${ }^{36}$ WeBer, Max, Economía y Sociedad II, segunda edición, segunda reimpresión, Fondo de Cultura Económica, México, 1974, pp. 706-707. Sobre este mismo punto es dable concluir que: "En la concepción de Weber encontramos varios criterios que nos ayudan a caracterizar un poder legítimo: en primer lugar, un poder es legítimo si sus mandatos son acatados y obedecidos como obligatorios, lo que quiere decir que la eficacia prueba y justifica la legitimidad del poder; otro criterio de legitimidad lo constituye el modo permanente como se ejerce el poder, recordemos que para que un grupo de poder sea tenido por una asociación política debe garantizar que se obedezca su ordenamiento en un territorio de forma continua mediante la amenaza de la coacción física; el tercer criterio de legitimidad es la legalidad, que se desprende de la célebre distinción weberiana entre poder (Macht) y dominación (Herrschaft), de la que se puede concluir que el poder legítimo (Herrschft) se distingue del poder de hecho (Macht) por estar regulado por normas". MARTínez FERRO, Hernán, "Legitimidad, dominación y derecho en la teoría sociológica del Estado de Max Weber", Revista Estudios Socio - Jurídicos, vol. 12, № 1, enero - junio, Universidad del Rosario, Bogotá D.C., 2010, p. 425.

${ }^{37}$ Ver: Habermas, Jürgen, Problemas de legitimación en el capitalismo tardío, Cátedra, Madrid, 1999, p. 165.

38 "Finalmente, hay que tener presente que los discursos jurídicos, cualquiera sea su modo de vinculación al derecho vigente, no pueden moverse en un universo cerrado de reglas jurídicas unívocamente fijadas. Esto es algo que se sigue de la propia estructuración del derecho moderno en reglas y principios. Muchos de estos principios son de naturaleza jurídica y simultáneamente de naturaleza moral, como fácilmente puede verse en el caso del derecho constitucional. Los principios morales del derecho natural racional se han convertido en los Estados constitucionales modernos en derecho positivo. Por eso las vías de fundamentación institucionalizadas mediante procedimientos jurídicos, cuando se las mira desde la perspectiva de una lógica de la argumentación, permanecen abiertas a discursos morales". Habermas, Jürgen, Facticidad y Validez. Sobre el derecho y el Estado democrático de derecho en términos de teoría del discurso, cuarta edición, Trotta, Madrid, 2005, p. 545.
} 
Es por ello que, siguiendo esas mismas trazas argumentales, Habermas expresa "la tesis de que sólo de una racionalidad procedimental Ilena de contenido moral puede extraer la legalidad su propia legitimidad"39. En consecuencia, el concepto de legitimidad habermasiano está atravesado por una legalidad que supera al iuspositivismo estricto y, en cambio, está impregnado de una teoría procedimental de la justicia, con elementos de mezcla entre derecho y moral. Por ello, "legitimidad significa que la pretensión que acompaña a un orden político de ser reconocido como correcto y justo no está desprovista de buenos argumentos; un orden legítimo merece el reconocimiento. Legitimidad significa el hecho del merecimiento de reconocimiento por parte de un orden político" ${ }^{\prime 40}$. En este mismo sentido, López Hernández comprendió la caracterización del orden político derivado del pensamiento habermasiano de la legitimidad, de esta manera: "1) La Constitución regula el proceso político a través de normas: mayoría, proceso parlamentario, ley electoral, etc. 2) La labor del Parlamento debe estar apoyada en una participación cada vez mayor de la población. 3) La calidad de la vida pública debe mejorar constantemente y en ello tienen especial importancia los medios de comunicación" ${ }^{\prime 41}$.

La legitimidad habermasiana parte de su teoría de la acción comunicativa ${ }^{42}$ para sustentar sus tesis de legitimidad, en donde la legitimación parte de un consenso social logrado a partir de la comunicación, en donde se concretan, de consuno, los contenidos materiales de justicia ${ }^{43}$.

La legitimidad hasta aquí analizada se refiere a la legitimidad en el orden político, mas no a la legitimidad en el ejercicio del poder político, la cual debe mirarse con la óptica del modelo de Estado definido por la Constitución Política. La legitimidad a la que se refieren autores como Ferrero, Weber o Habermas corresponde a la legitimidad del Estado y de su correspondiente orden

\footnotetext{
${ }^{39}$ Habermas, Facticidad y Validez, cit. nota n. 38, p. 536.

${ }^{40}$ Habermas, Jürgen., La reconstrucción del materialismo histórico, Taurus, Madrid, 1981, p. 243.

${ }^{41}$ López HeRnÁndez, "El concepto", cit. nota n. 21, p. 161.

42 "Habermas actualiza estos presupuestos a partir de una teoría comunicativa de la acción, donde los individuos, desde condiciones pragmáticas universales de entendimiento, interactúan construyendo un consenso racional basado en argumentos y produciendo así las decisiones consideradas justas. Por tanto, el contenido normativo justo se construye íntegramente desde la pureza del procedimiento democrático a través de un proceso de diálogo en una situación ideal de habla. Para Habermas la legitimación es un proceso de comunicación, cuyo objetivo es la búsqueda del entendimiento, basado en condiciones pragmáticas ideales que posibilitan dicho entendimiento y sin que exista ninguna coacción externa, incluida la del propio poder político. Este procedimiento no sólo es formalmente correcto, sino que, a través de él, el grupo social acuerda los contenidos materiales de justicia que considera convenientes". López HeRnÁnDEZ, "El concepto", cit. nota n. 21, p. 162.

${ }^{43}$ Ver: Del Águila, Rafael, "La política: el poder y la legitimidad", en Del Águila, Rafael (ed.), Manual de Ciencia Política, segunda edición, Trotta, Madrid, 2000, pp. 29-34.
} 
político, es decir, a la justificación del Estado mismo, de su existencia y de la necesidad de un orden jurídico-político derivado del contrato social sobre el que se estructura el Estado moderno, por ello, al realizar una arqueología del concepto legitimidad sobre el que Weber o Habermas cifran el punto de partida de sus disquisiciones, se encuentra a autores como Hobbes, Locke, Rousseau o Montiesqueu, por nombrar sólo a los contractualistas más conocidos, dado que son ellos los que construyen la teoría política moderna sobre conceptos fundamentales como el de legitimidad ${ }^{44}$. Así las cosas, se entiende que la legitimidad del orden político se corresponde con aquella derivada del ejercicio de las libertades individuales propias del Estado moderno, la misma libertad de los modernos a la que se refería Benjamín Constant en su célebre discurso "De la libertad de los antiguos comparada con la de los modernos" ${ }^{\prime 4}$.

Esa legitimidad del orden político es sustancialmente diferente a la legitimidad en el ejercicio del poder político, que constituye el propósito de abordaje de este estudio. Ésta parte de la base de que el orden político en el que se va a ejercer el poder goza de legitimidad, por lo menos aparente, derivada del cumplimiento de un orden constitucional que supera el iuspositivismo estricto y que deviene de un ejercicio deliberativo en donde se ha acudido a teorías procedimentales de la justicia que han inyectado dosis de moralidad colectiva a las disposiciones normativas, con un marco sólido en materia de principios, para hablar en términos habermasianos ${ }^{46}$.

La legitimidad en el ejercicio del poder político implica el cumplimiento de los fines definidos por el propio Estado como condicionantes de su accionar, es lo que autores como José Nun denominan como legitimidad sustantiva ${ }^{47}$.En el

\footnotetext{
${ }^{44}$ López Hernández, "El concepto", cit. nota n. 21, pp. 156-158.

${ }^{45}$ Constant, Benjamín, Escritos Políticos, Centro de Estudios Constitucionales, Madrid, 1989. En este discurso Benjamín Constant distingue entre dos tipos de libertad, la de los antiguos, particularmente los griegos, que se refiere, casi que exclusivamente, a la posibilidad de participar en los asuntos públicos, y la libertad de los modernos, que implica el ejercicio pleno de las libertades individuales sobre cuya garantía se edificó el estado moderno de corte liberal, incluyendo la posibilidad de participar en la conformación del gobierno.

46 "Habermas considera que la democracia produce resultados justos y legítimos en la medida en que la construcción de la razón pública se haga entre agentes libres y racionales y sin interferencias comunicativas. Pero la legitimidad de la democracia reposa en el ordenamiento jurídico y no en la deliberación, por cuanto se presume que toda decisión es justa y legítima siempre y cuando se haga respetando las reglas de la democracia". Cuervo, Jorge Iván, "¿Democracia sin representación? Apuntes para una caracterización de la democracia no deliberativa", en Vela Orbegozo, Bernardo, Dilemas de la Política, Tomo I, Universidad Externado de Colombia, Bogotá D.C., 2007, p. 174.

47 "Quiero decir: una cosa es ser miembro de un Estado, sujeto a sus autoridades y a sus leyes en tanto mero habitante de un territorio; y otra muy diferente gozar de todos los derechos de ciudadanía y ser definido (y definirse) como participante activo en una colectividad guiada por un propósito declaradamente común. Para lo primero alcanza con reconocerle al Estado una legitimidad formal; lo segundo plantea un problema suplementario y crucial de su legitimidad sustantiva, conforme ese Estado cumpla
} 
caso colombiano, el modelo constitucional de Estado Social de Derecho conlleva a que la legitimidad en el ejercicio del poder político implique que todo el accionar del aparato estatal debe orientar su sentido hacia la satisfacción de los fines esenciales del Estado que aparecen en el artículo $2^{\circ}$ de la Constitución Política de $1991^{48}$ y que la jurisprudencia constitucional ha concebido como valores constitucionales ${ }^{49}$.

En suma, se distingue entre dos tipos de legitimidad: i) una legitimidad formal, que deviene del orden político y que comprende aspectos procedimentales relacionados con la forma en que los individuos llegan a detentar el poder político, es decir, el ejercicio electoral en sí, en un sistema democrático, y ii) una legitimidad material, que se refiere al ejercicio del poder en sí, y que está orientada al cumplimiento de los objetivos definidos como propios por el modelo de Estado adoptado, lo que en el marco del Estado Social de Derecho significa la satisfacción de los postulados contenidos en la parte dogmática de la Constitución por el aparato orgánico definido en el mismo texto superior, ese es el leitmotiv, de la organización de la administración pública de acuerdo con el diseño del constituyente colombiano de 1991, por lo que los procedimientos administrativos aparecen vinculados irremediablemente con la teleología constitucional "en cuanto mecanismos para la satisfacción de estos cometidos" 50 .

Estos dos tipos de legitimidad política contemporánea se deducen del análisis de la legitimidad en el campo jurídico, y de alguna manera conllevan a la evocación de los principios de legitimidad enunciados por Ferrero ${ }^{51}$, particularmente el principio democrático y el principio electivo, de cuya comunión el autor dedujo una clave explicativa de los regímenes políticos democráticos en el siglo XX, como contraposición al autoritarismo fascista que le tocó vivir. Igualmente resulta inevitable pensar en el antecedente que

\footnotetext{
o no con los objetivos que invoca como propios o posea, en caso contrario, una credibilidad suficiente como para que resulte verosímil que logrará satisfacerlos en algún momento más o menos próximo". Nun, José, Democracia: ¿gobierno del pueblo o gobierno de los políticos?, primera edición, tercera reimpresión, Fondo de Cultura Económica, Buenos Aires, 2002, p. 98.

48 "ARTÍCULO $2^{\circ}$. Son fines esenciales del Estado: servir a la comunidad, promover la prosperidad general y garantizar la efectividad de los principios, derechos y deberes consagrados en la Constitución; facilitar la participación de todos en las decisiones que los afectan y en la vida económica, política, administrativa y cultural de la Nación; defender la independencia nacional, mantener la integridad territorial y asegurar la convivencia pacífica y la vigencia de un orden justo.

Las autoridades de la República están instituidas para proteger a todas las personas residentes en Colombia, en su vida, honra, bienes, creencias, y demás derechos y libertades, y para asegurar el cumplimiento de los deberes sociales del Estado y de los particulares".

${ }^{49}$ Al respecto ver la precitada Sentencia T-406 de 1992, M.P. Ciro Angarita Barón.

50 Santofimio Gamboa, Jaime Orlando, Procedimientos administrativos y tecnología, Universidad Externado de Colombia, Bogotá D.C., 2011, p. 33.

${ }^{51}$ Ferrero, El Poder, cit. nota n. 25.
} 
comprenden las dos legitimidades que se desprenden de la descripción de las tiranías hecha por el jurista Bartolo: legitimidad de título y legitimidad de ejercicio, las cuales surgen, precisamente, de las dos clases de poder ilegítimo o tiranía descritas por este autor: ex defectutituli y ex parte exercitii ${ }^{52}$, sin duda alguna, los contenidos de estas dos legitimidades medievales encuentran plena correspondencia con los contenidos de la legitimidad formal y la legitimidad material aludidas. A su vez, Pierre Rosanvallon encuentra estos dos tipos de legitimidad enlazados en la consolidación de los regímenes democráticos: "la legitimidad derivada del reconocimiento social de un poder y la legitimidad como adecuación a una norma o valores. A partir de comienzos del siglo XX, esas dos formas cruzadas de legitimidad -procedimental y sustancial- le dieron un cierto asentamiento a los regímenes democráticos" ${ }^{\prime 53}$. Para este autor en la década de 1980 se dio un giro que obligó a una resignificación de la legitimidad en términos de atender menos a un carácter procedimental y profundizar en las relaciones propias de la democracia, en una "reformulación latente de los términos en los cuales se aprehende el imperativo democrático de expresión de la generalidad social" 54 , que en últimas viene a tener correspondencia con la plena satisfacción de los cometidos del Estado contemporáneo, cercano al paradigma de Estado Constitucional ${ }^{55}$, dado que conlleva amplias dosis de moralidad en su ordenamiento jurídico-político, que para el Estado Social de Derecho colombiano implica el cumplimiento de los fines definidos por la teleología constitucional.

\footnotetext{
${ }^{52}$ Ver: Boвbio, Norberto, Teoría de las formas de gobierno en la historia del pensamiento político, Fondo de Cultura Económica, México, 1996, pp. 29-30.

${ }^{53}$ Rosanvallon, Pierre, La legitimidad democrática: imparcialidad, reflexividad, proximidad, Manantial, Buenos Aires, 2009, p. 25.

${ }^{54}$ Rosanvallon, La legitimidad democrática, cit. nota n. 53, p. 27.

${ }^{55}$ Para Ferrajoli, el Estado Constitucional no es más que la aplicación del modelo garantista, en donde el Estado tiene como fin último la protección de los derechos fundamentales de los individuos, e implica una sujeción al derecho positivo emanado de la Constitución. Al respecto ver: FerRAjOLI, Luigi, Derechos y garantías. La ley del más débil, cuarta edición, Trotta, Madrid, 2004, p. 19. El profesor chileno José Luis Cea Egaña resume el significado del paradigma de Estado Constitucional de esta manera: "Rectamente entendido, el paradigma del Estado Constitucional de Derecho equivale a una reformulación, desde sus bases hasta sus más elevados y determinantes objetivos, de lo que es el Derecho en su naturaleza y génesis, en su interpretación y aplicación, incluyendo las fuentes, la hermenéutica, el rol del Estado en el ordenamiento jurídico, las conexiones con la Sociedad Civil en democracia y otros vectores de semejante importancia. De ese paradigma es criterio esencial la mayor independencia del Derecho con respecto a la soberanía, única manera que aquél se imponga a ésta, postulado que debe seguir en el orden jurídico interno y también, no cabe duda, en el ámbito internacional". CEA Egaña, José Luis, "Sobre el Estado constitucional de derecho como paradigma jurídico", Revista de Derecho, V. 16, julio, Universidad Austral de Chile, Valdivia, 2004. En: http://www.scielo.cl/scielo.php?script=sci_arttext\&pi $\mathrm{d}=S 071809502004000100020 \& \operatorname{lng}=\mathrm{es} \& \mathrm{nrm}=\mathrm{iso} \&$ tlng=es [visitado el 03/08/2013].
} 


\section{CoRrupCión Y CLIENTELISMO:}

de la captura a la ilegitimidad material en el Estado Social De Derecho

En el Estado Social de Derecho el concepto de ilegitimidad material se refiere al hecho de que las estructuras que edifican el Estado no están cumpliendo con los cometidos definidos por la dogmática constitucional. Esto puede darse por una multiplicidad de factores: anteposición de intereses privados en la configuración de normas y políticas públicas, elección de representantes que provienen de grupos ilegales, corrupción administrativa y configuración del sistema democrático a partir de relaciones clientelares, entre otros. Estos factores pueden Ilevar a la captura del Estado (CdE) o a la reconfiguración cooptada del Estado $(\mathrm{RCdE})^{56}$, que son entendidas como manifestaciones concretas de la ilegitimidad material en el Estado.

El concepto de captura del Estado (CdE), es esbozado por el Banco Mundial como: "La acción de individuos, grupos o firmas, en el sector público y privado, que influyen en la formación de leyes, regulaciones, decretos y otras políticas del gobierno, para su propio beneficio como resultado de provisiones ilícitas y no transparentes de beneficios privados otorgados a funcionarios públicos ${ }^{\prime \prime 57}$. Esta concepción de captura ${ }^{58}$ bien puede denominarse como clásica, y en la práctica se circunscribe a aspectos puntualmente económicos ${ }^{59}$, en donde el sujeto de regulación efectúa la CdE con el fin de extraer "rentas del Estado para el beneficio de individuos privados, firmas o sectores mediante la distorsión del marco legal y regulatorio" 60 , aun cuando se debe tener presente que el fenómeno de la captura también se presenta en otros ámbitos como el legislativo, el jurisdiccional y en la configuración de la política pública, en general. Igualmente se aclara que, en un contexto como el colombiano, los agentes captores pueden ser legales con intereses particulares o ilegales con intereses criminales, en donde son los actores ilegales quienes capturan a los actores legales, frecuentemente ${ }^{61}$. En este sentido, fenómenos como el de la parapolítica ${ }^{62}$ demuestran que, por

\footnotetext{
${ }^{56}$ En adelante se escribirá CdE para referirse a la captura del Estado y RCdE para significar la reconfiguración cooptada del Estado.

${ }^{57}$ Cita tomada de Garay et al., La Captura, cit. nota n. 7, p. 16.

${ }^{58}$ En este sentido también puede consultarse a Membreño Cedillo, Mario, Qué se entiende por captura de Estado, Consejo Nacional Anticorrupción, Tegucigalpa, 2008.

${ }^{59}$ Bоввіо, Norberto, El futuro, cit. nota n. 19, pp. 80-83, Ilama a este fenómeno como "subgobierno", y cuando se está en presencia de captores de origen ilegal lo denomina "criptogobierno".

${ }^{60}$ Garay et al., La Captura, cit. nota n. 7, p. 18.

${ }^{61}$ Garay et al., La Captura, cit. nota n. 7, p. 20.

${ }^{62}$ La parapolítica es definida como "un fenómeno nacional de captura masiva de la representación política y el poder público por parte del narcotráfico y el paramilitarismo, a través de políticos y otros servidores públicos en los niveles local, regional y nacional". LóPEz, Claudia y SEVILLANo, Óscar,
} 
el contrario, en los últimos años es mucho más frecuente la captura invertida, es decir, de los actores legales hacia los ilegales ${ }^{63}$.

A su vez, el concepto de reconfiguración cooptada del Estado (RCdE) tiene que ver con la modificación del régimen desde el interior del mismo, fenómeno que es definido como: "La acción de organizaciones legales e ilegales que mediante prácticas ilegítimas, buscan modificar, desde adentro, el régimen político de manera sistémica e influir en la formación, modificación, interpretación y aplicación de las reglas de juego y de las políticas públicas, para obtener beneficios sostenibles y lograr que sus intereses sean validados política y legalmente, y legitimados socialmente en el largo plazo, aunque éstos no obedezcan al interés rector del bienestar social"64.

De acuerdo con las conceptualizaciones presentadas, tanto la CdE como la RCdE son conceptos diferentes, con contenidos distintos, en donde "la captura opera desde fuera del sistema, mientras que la reconfiguración lo hace desde dentro del mismo" ${ }^{\prime 65}$. Ello implica que son conceptos con claros factores diferenciales pero con un impacto común en la ilegitimidad material en el Estado Social de Derecho; es más, según los mismos autores "la RCdE pareciese ser un momento más avanzado de la $\mathrm{CdE}$ en el cual los distintos actores ilegales ponen al Estado a su servicio" ${ }^{\prime 66}$. Aun así, no puede hablarse de ellos como fenómenos secuenciales y lineales, ya que dependen de la relación entre actores legales e ilegales, sus motivos y su margen de operación y reglas establecidas ${ }^{67}$.

\footnotetext{
"Balance político de la parapolítica", Revista Arcanos, № 14, diciembre, Corporación Nuevo Arco Iris, Bogotá D.C., 2008, p. 62. En: http://www.arcoiris.com.co/wp-content/uploads/2011/arcanos/ revista_ARCANOS_14.pdf [visitado el 22/11/2012].

63 "Los hallazgos coinciden con los supuestos teóricos en cuanto a que las formas de captura invertida, y también de captura usual, incrementan la exposición penal tanto de los actores supuestamente legales, como los políticos, como de sus aliados ilegales, narcotraficantes y grupos armados ilegales, y en cuanto a que a ambos se les ejecuta parte de ese riesgo. Sin embargo, la evidencia indica que los legales usualmente logran minimizar su exposición penal, mientras que tienen ventajas para maximizar y ejecutar el riesgo de exposición penal de sus socios ilegales. Los ilegales, además, tienen serios problemas de 'riesgo moral' típicos de la relación agente/principal para hacer cumplir a los políticos su parte de lo pactado. Aunque los ilegales tienen en teoría el recurso diferencial y eficaz del chantaje y la violencia, los políticos también acceden a esos recursos por otras vías y no dudan en usarlos. Son usualmente los políticos, no sus socios ilegales, quienes logran prevalecer y legitimarse en el largo plazo. Los unos terminan extraditados y los otros siguen gobernando". LóPEZ, Claudia, "La refundación de la patria, de la teoría a la evidencia", en LóPEZ, Claudia (ed.), Y refundaron la patria... De cómo mafiosos y políticos reconfiguraron el Estado Colombiano, Random House Mondadori-Corporación Nuevo Arco Iris, Bogotá D.C., 2010, p. 46.

${ }^{64}$ Garay et al., La Captura, cit. nota. n. 7, p. 96.

${ }^{65}$ García Villegas, Mauricio y Revelo Rebolledo, Javier Eduardo, Estado Alterado. Clientelismo, mafias y debilidad institucional en Colombia, Dejusticia, Bogotá D.C., 2010, p. 67.

${ }^{66}$ García Villegas y Revelo Rebolledo, Estado Alterado, cit. nota n. 65, p. 67.

${ }^{67}$ LÓPEZ, "La refundación", cit. nota. n. 63, p. 45.
} 
Para algunos, en Colombia se ha pasado de unas prácticas de CdE a RCdE, por lo que, según los defensores de esta tesis ${ }^{68}$, se estaría en presencia de la fase inicial de la segunda, por parte de actores ilegales, que comenzó con el auge y la penetración del narcotráfico en las esferas de decisión política y llegó hasta propósitos de refundación de la patria, por parte de organizaciones paramilitares que implicaban, en la práctica, la $\mathrm{RCdE}$, valiéndose de estrategias como la penetración en el legislativo y en ejecutivos territoriales, por ejemplo, en el fenómeno conocido como parapolítica, caso en el cual el actuar de paramilitares y agentes estatales comenzó con prácticas de CdE, pero estuvo orientado a consolidar una $\mathrm{RCdE}$, en tanto que lo pretendido fue la modificación del régimen desde el interior del mismo; por eso la tesis de la refundación de la patria. Si bien es cierto que la parapolítica, en la práctica, no implicó una RCdE, este fenómeno conllevó a que se presentaran altos niveles de $\mathrm{CdE}$, no sólo en el legislativo, sino también en el ejecutivo, incluyendo las administraciones territoriales, y en lo judicial. Esta CdE implicaba una apropiación de las instituciones del Estado, manteniendo la apariencia de la legalidad en su quehacer ${ }^{69}$.

La CdE no aparece por sí misma, sino en virtud de una serie de prácticas generadas por los agentes captores, siendo el clientelismo político un fenómeno generador de prácticas orientadas hacia la $\mathrm{CdE}$, en tanto que lo que se busca con éste es la apropiación de un sector de la institucionalidad con miras a la consolidación de una fuente de recursos, burocráticos y económicos, que permita el sostenimiento de las estructuras políticas de los agentes captores, aprovechando para ello las posibilidades de decisión legislativa y política en la satisfacción de los intereses particulares de grupos de poder que suelen estar ligados a movimientos o partidos políticos, que se nutren de la institución capturada para llevar a cabo una depredación de recursos públicos. Esta situación tiene una incidencia directa en la legitimidad material en el Estado, por cuanto no se permite la plena satisfacción de los fines esenciales del Estado Social de Derecho; de tal suerte que existe un aparejamiento entre los fenómenos de corrupción y clientelismo, dado que de alguna manera se convierten en simbióticos, en tanto que se reproducen uno a partir del otro, no porque sean lo mismo, sino porque los grupos que llegan al poder mediante prácticas de

\footnotetext{
${ }^{68}$ Garay et al., La Captura, cit. nota. n. 7, p. 118.

${ }^{69}$ García Villegas y Revelo Rebolledo explican al respecto: "Es importante tener presente que la mafia y los paramilitares no pretenden, como la guerrilla, cambiar las instituciones, sino que, por el contrario, intentan que esas instituciones se mantengan con todas sus formalidades y sus rutinas. Su propósito central es la captura institucional sin afectar su funcionamiento aparente. Buscan apropiarse de las instituciones del Estado, sin cambiarlas, solo haciendo que ellas sigan sus propósitos". García VilleGAS y Revelo Rebolledo, Estado Alterado, cit. nota n. 65, p. 103.
} 
clientelismo, como partidos y movimientos políticos ${ }^{70}$, por ejemplo, utilizan a la corrupción para financiar y consolidar su permanencia en el poder, por lo menos en el nicho institucional abierto, operando de esta forma el otro fenómeno descrito, el de la $\mathrm{CdE}$, que conlleva a una ilegitimidad material en el modelo de estado definido por el constituyente.

En suma, se tiene que las prácticas clientelares son generadoras de corrupción, en tanto que permiten que el ganador de las elecciones y, por ende, el orientador de la agenda política durante el cuatrienio, reproduzca durante su administración prácticas tendientes a mantener las estructuras sociales de la misma manera, un statu quo orientado al afianzamiento del poder político a partir del mantenimiento en las condiciones del mercado electoral ${ }^{71}$, es decir, que existe una relación directamente proporcional entre corrupción y pobre$\mathrm{za}^{72}$. Esto se explica en la medida en que siendo los pobres los mismos pobres, y no teniendo posibilidades de ascenso social a través del goce efectivo de las políticas públicas derivadas del cumplimiento de los cometidos estatales, éstos mantendrán la clientela que necesita el patrón, en aras de sostener al agente captor, lo cual deriva en situaciones como que el voto no incrementa su costo en elecciones futuras, además del mantenimiento, y posible incremento, de la

\footnotetext{
${ }^{70}$ La relación entre corrupción y partidos políticos es explicada por Donatella Della Porta de esta forma: "Resumiendo, en los sistemas de corrupción difundida, los partidos políticos no sólo socializan para lo ilícito, reduciendo los costos morales de la corrupción, sino que además aseguran, gracias a la difusión de la corrupción en todas las áreas geográficas, en los diferentes organismos públicos y en los diversos sectores de la administración pública, una especie de 'repetición del juego' corrupto: el que respete los acuerdos ilícitos podrá seguir haciendo negocios con la administración pública; el que abandone la causa una vez, será excluido por siempre del mercado de las adquisiciones gubernamentales. Además, llegando a un acuerdo entre sí, mayoría y oposición reducen los riesgos materiales ligados a la identificación de la contraparte y la negociación de la comisión. Controlando los nombramientos en todos los organismos públicos, los partidos pueden generalizar la 'matraca', transformando lo ilícito de excepción en praxis difundida con sus normas compartidas, y garantizando la continuidad del sistema en el tiempo, no obstante el hecho de que el personal político se rote en la administración pública. Esto equivale a decir que los partidos asumen una función de garantes de pactos ilegales, participando en aquellas operaciones en las que se requiere una 'certificación de la confianza, o bien en las que, para obtener un beneficio, se usan promesas de otros, las cuales deben garantizarse de alguna manera'". DeLLA PORTA, Donatella, "Partidos políticos y corrupción. Reflexiones sobre el caso italiano", Revista Nueva Sociedad, № 145, septiembre-octubre, Fundación Friedrich Ebert, Buenos Aires, 1996, pp. 13-14. En: http://nuso.org/upload/articulos/2535_1.pdf [visitado el $17 / 01 / 2013]$.

${ }^{71}$ Sobre este punto se puede consultar a Cendales, Andrés, "¿Son los pobres las únicas víctimas con la compra de votos? Un caso de competencia política con expropiación generalizada", Revista Cuadernos de Economía, vol. 31, № 56, Universidad Nacional de Colombia, Bogotá D.C., 2012, pp. 282-283.

${ }^{72}$ Un interesante estudio comparativo entre varios Departamentos de Colombia puede encontrarse en: Saíz Vélez, Jorge Enrique; Mantilla Bautista, Sergio Iván y Cárdenas Beltrán, Jesús María, "Efectos de la corrupción sobre la criminalidad, el crecimiento económico y la pobreza: una evidencia para seis departamentos de Colombia", Revista Criterio Libre, vol. 10, № 16, enero-junio, Universidad Libre de Colombia, Bogotá D.C., 2012.
} 
clientela ${ }^{73}$, lo cual implica, en los términos de este texto, una consolidación de la CdE a partir de prácticas emparentadas con los fenómenos de clientelismo y corrupción.

Así las cosas, el proceso de preservación de estructuras sociales de pobreza implica la ejecución de un presupuesto en donde la inversión social debe ser mínima, aun cuando en apariencia sea diferente; por ello, los presupuestos están configurados sobre una multiplicidad de rubros de donde se extractan tres elementos importantes para el análisis: un alto porcentaje en gastos de funcionamiento, lo que permite la consolidación de relaciones de patronazgo político a partir de la asignación de "cuotas burocráticas"; un porcentaje igualmente alto en infraestructura, en sectores diferentes a los deprimidos, que son los propicios para prácticas clientelares como la compra de votos; y un porcentaje en inversión social, pero básicamente sobre políticas asistencialistas propias de un Estado paternalista, los cuales permiten mantener la clientela pero en las mismas condiciones socioeconómicas, al mejor estilo lampedusano de que todo cambie para que todo se quede como está. Esto, sin contar con que una buena porción de los recursos son objeto de depredación a partir de prácticas como la sustracción directa de dineros del patrimonio público o de la exigencia de comisiones para facilitar la asignación de contratos, o el pago de sobornos con el mismo fin, lo cual aparece suficientemente documentado en casos como el del "carrusel de la contratación" auspiciado por los hermanos Moreno Rojas desde la Alcaldía Mayor de Bogotá74, así las cosas "el monto y la incidencia de los sobornos está relacionado con el nivel general de los beneficios dispo-

\footnotetext{
${ }^{73}$ Sobre este punto se pueden consultar, entre otros, CENDALES, "Son los pobres", cit. nota. n. 71, pp. 281-283, lo mismo que Cendales, Andrés y Jiménez, Alfi, "The dark side of clientelism", ponencia presentada en The 24th Stony Brook Game Theory Festival of the Game Theory Society, july 8-12, Stony Brook University, New York, 2013. En: http://www.gtcenter.org/Downloads/Conf/Andres\% 20Cendales1600.pdf_[visitado el 19/08/2013]. También aporta algunos elementos susceptibles de tener presentes, la lectura de VolintiRu, Clara, "Clientelism and democratic accountability", conferencia dictada en Political Studies Association Graduate Network Conference, december, Newcastle, England, 2010. En: http://www.sar.org.ro/wp-content/uploads/2012/01/Clientelism-and-Democratic-Accountability. pdf [visitado el 17/08/2013].

${ }^{74}$ Por "carrusel de la contratación" se conoce por la opinión pública colombiana a un fenómeno de CdE vivido por el Distrito Capital de Bogotá durante el período de gobierno del Alcalde Mayor Samuel Moreno Rojas, quien, junto con su hermano Iván, para la fecha Senador de la República, lideraron una organización en la sombra, que en la práctica operó como un gobierno paralelo, a efectos de depredar los recursos públicos a través del saqueo sistemático de instituciones como el IDU o la UAESP, y la asignación de contratos a cambio de enormes comisiones y porcentajes, muchos de los cuales no cumplían con el mínimo de los requisitos legales exigidos. Sobre este punto bien vale la pena revisar la investigación periodística adelantada por la Revista Semana titulada "El segundo Bogotazo", en donde se da cuenta de la depredación de recursos públicos a que fue sometida la capital de la República de Colombia durante el mandato de Samuel Moreno Rojas. "El Segundo Bogotazo", Revista Semana, edición 1615, 13 de abril de 2013. En: http://www.semana.com/nacion/articulo/el-segundobogotazo/339828-3 [visitado el 14/04/2013].
} 
nibles y con el poder relativo de negociación de los políticos y funcionarios potencialmente corruptos ${ }^{\prime 75}$. Por ello resulta fundamental hacer unas breves conceptualizaciones en torno a la corrupción a fin de poder emparentarla con el fenómeno de CdE.

El concepto corrupción resulta polisémico y multivocista y se puede mirar desde la ética, la política, la economía o el derecho. La corrupción implica no hacer lo que se está obligado a hacer, para atender otros intereses diferentes a los del servicio público ${ }^{76}$. La corrupción se encuentra vinculada con los procedimientos administrativos, dado que ese es el escenario propicio para la realización de las prácticas orientadas hacia la satisfacción de los intereses particulares de quienes fomentan o financian estas prácticas, a través de la asignación de comisiones o de sobornos. Por ello aparece que "la corrupción es resultado de la forma en que es diseñada la relación entre las organizaciones del Estado y los espacios de incertidumbre que los actores que implementan obtienen a partir del propio diseño de las reglas, tanto del trámite como del proceso de implementación" ${ }^{\prime 77}$.

La corrupción ostenta una naturaleza transaccional ${ }^{78}$, lo que facilita la captura de instituciones estatales, como lo demuestra el conocido estudio codirigido

\footnotetext{
${ }^{75}$ ArtaVia Araya, Fernando, "Decisiones públicas, beneficios privados. Consideraciones teóricas en torno a la corrupción", Revista de Ciencias Sociales, vol. I, No 119, Universidad de Costa Rica, San José, 2008, p. 18. En: http://163.178.170.74/wp-content/revistas/119/01-Artavia-Decisiones\%20P\% C3\% BAblicas.pdf [visitado el 29/01/2013].

${ }^{76}$ La caracterización de la corrupción elaborada por Cazzola resulta bastante completa: "La definición que me parece más útil para los fines de una reconstrucción empírica del fenómeno es la siguiente: para que exista corrupción, en tanto intercambio de favores bajo la forma de trueque o de intercambio social, es necesaria la presencia de cuatro elementos constitutivos: 1) que exista la violación de normas y de reglas sancionadas normativamente; 2) que dicha violación suceda en el transcurso de un intercambio que se desarrolla en modo clandestino entre arenas políticas y mercado económico; 3) que la violación tenga como finalidad la apropiación por parte de individuos o grupos que actúan en las arenas políticas o en el mercado económico de recursos de uso o de intercambio (dinero, prestaciones, influencia, etcétera) de origen público para su utilización no prevista normativamente; 4) que todo esto tenga como consecuencia (deseada o aceptada) a nivel político modificar las relaciones de poder en los procesos decisionales, así como acrecentar la asimetría entre poder y responsabilidad (para algunos grupos o individuos el poder aumenta sin que esto comporte una mayor responsabilidad), mientras que a nivel social y económico, a la imposibilidad 'legal' de hacer respetar los contratos de intercambio sobreviene la violencia como elemento de sanción". CAzzolA, Franco, "Conceptualizando la corrupción", Revista Metapolítica, № 45, enero-febrero, Centro de Estudios de Política Comparada, México, 2006, p. 44.

${ }_{77}$ Vértiz Galván, Miguel Ángel, "El combate a la corrupción en los procedimientos administrativos. Una aproximación teórica", Revista Gestión y Política Pública, vol. 9, № 2, Centro de Investigación y Docencia Económicas, México, 2000, p. 308. En: http://www.gestionypoliticapublica.cide.edu/ num_anteriores/Vol. IX_No.II_2dosem/VGM_Vol.9_No.II_2sem.pdf [visitado el 16/01/2013].
}

${ }^{78}$ La naturaleza transaccional de la corrupción es explicitada como sigue: "Por consiguiente, la corrupción puede ser, ante todo, definida como un intercambio clandestino entre dos 'mercados', el político y/o administrativo y el mercado económico y social. Es un intercambio oculto por el hecho 
"La legitimidad en el ejercicio del poder político en el Estado Social de Derecho.

por Mauricio García Villegas y Javier Eduardo Revelo Rebolledo ${ }^{79}$ en donde se da cuenta de la captura de ciertas entidades colombianas como el Consejo Superior de la Judicatura, el Consejo Nacional Electoral o la extinta Comisión Nacional de Televisión.

A su vez, el clientelismo también ostenta una naturaleza transaccional, dada la "relación diádica entre patrón y cliente" ${ }^{\text {" }}$, en donde existe una dependencia mutua de ambos sujetos ${ }^{81}$, en donde el patrón requiere del cliente para mantener el poder y el cliente requiere del patrón para el otorgamiento de los beneficios prometidos por éste, bien sea dinero u otras dádivas en especie, incluyendo la asignación de cuotas burocráticas en la consolidación de relaciones de patronazgo político. Sin ánimo de ofrecer una descripción completa del concepto ${ }^{82}$, ni la categorización que hoy exhibe la ciencia política ${ }^{83}$, sino más bien de realizar

de que viola normas públicas, jurídicas y éticas, y sacrifica el interés general por los intereses privados (personales, corporativos, de partido etcétera). Esta transacción, que permite a los privados acceder a recursos públicos (contratos, financiamientos, decisiones...) en manera privilegiada y mediada (ausencia de transparencia, de competencia) ofrece a los personajes públicos corruptos beneficios materiales presentes o futuros para sí mismos o para la organización de la cual forman parte". DeLLA PORTA, Donatella y MÉnY, Yves, "Democracia y Corrupción", Revista Metapolítica, № 45, enero-febrero, Centro de Estudios de Política Comparada, México, 2006, p. 38.

${ }^{79}$ García Villegeas, Mauricio y Revelo Rebolledo, Javier Eduardo (Codir.), Mayorías sin democracia. Desequilibrio de poderes y Estado de derecho en Colombia, 2002-2009, Dejusticia, Bogotá D.C., 2009.

${ }^{80}$ ACUÑA CHAVERRI, Iván Anselmo, "Elementos conceptuales del clientelismo político y sus repercusiones en la democracia", Revista Reflexiones, vol. 2, № 88, Universidad de Costa Rica, San José, 2009, p. 30. En: http://www.reflexiones.fcs.ucr.ac.cr/images/edicion_88_2_09/clientelismoPolitico RepercusionesDemocracia.pdf [visitado el 10/12/2012].

81 "Es un hecho que el patrón depende también de sus clientes, aunque solamente como se puede depender de un rebaño político. Pero Platón ha dicho, con razón, que nadie es malo por voluntad. En realidad, los países del Sur están todos marcados, en la aurora del liberalismo latino, por unos mecanismos que transforman el clientelismo en recurso providencial, o por lo menos en ingrediente de alguna manera natural de una combinación política salvadora en los medios en que el Estado no ofrece salvación. El pecado del voto comprado no sobreviene sino más tarde, cuando se agotan las virtudes de adhesión gregaria a los deseos del patriarca". HeRMET, Guy, En las fronteras de la democracia, primera edición, segunda reimpresión, Fondo de Cultura Económica, México, 1996, p. 88.

${ }^{82}$ Las prácticas clientelistas aparecen enquistadas en la historia del quehacer político colombiano, de hecho, existen estudios que ubican su aparición en las primeras décadas de republicanismo en el siglo XIX. Sobre este punto se puede ver: TORRes PRECIADO, Javier Fernando, Entre la participación y la exclusión: el sistema político 1848-1885, Universidad de Los Andes, Bogotá D.C., 2009.

${ }^{83} \mathrm{Al}$ respecto pueden consultarse: DÁVILA, Andrés y DeLGADO, Natalia, "La metamorfosis del sistema político colombiano: ¿clientelismo de mercado o nueva forma de intermediación”, en GutiérRez SANín, Francisco (Comp. ), Degradación o cambio. Evolución del sistema político colombiano, IEPRI-Editorial Norma, Bogotá D.C., 2002; SCHrÖTER, Bárbara, "Clientelismo político: ¿existe el fantasma y cómo se viste?", Revista Mexicana de Sociología, vol. 72, № 1, enero-marzo, Universidad Nacional Autónoma de México-Instituto de Investigaciones Sociales, México, 2010. En: http://www.ejournal.unam. $\mathrm{mx} / \mathrm{rms} / 2010-1 / \mathrm{RMS010000105.pdf} \mathrm{[visitado} \mathrm{el} \mathrm{08/12/2012].} \mathrm{A} \mathrm{su} \mathrm{vez,} \mathrm{para} \mathrm{el} \mathrm{caso} \mathrm{colombiano} \mathrm{se}$ habla de un clientelismo armado, como una subclase de clientelismo, derivado del impacto político 
una aproximación que permita obtener los elementos mínimos que habiliten el aparejamiento entre clientelismo y corrupción como factores detonantes de la ilegitimidad material en el Estado Social de Derecho, a partir del fenómeno de $\mathrm{CdE}$, se puede definir al clientelismo como "aquellas relaciones informales de intercambio recíproco y mutuamente benéfico de favores entre dos sujetos, basadas en una amistad instrumental, desigualdad, diferencia de poder y control de recursos, en las que existe un patrón y un cliente: el patrón proporciona bienes materiales, protección y acceso a recursos diversos y el cliente ofrece a cambio servicios personales, lealtad, apoyo político o votos" ${ }^{\prime \prime 4}$.

La lealtad constituye uno de los elementos esenciales del clientelismo, en tanto que le permite legitimarse a partir de la justificación del ejercicio del poder por los representantes elegidos, por eso no sólo aparece como un intercambio de dinero o favores por votos, "sino como actos los cuales contienen objetos, palabras, acciones distributivas y públicas" ${ }^{\prime \prime 5}$. Luego, entonces, se puede decir que el clientelismo se legitima en apariencia a partir del resultado obtenido: la elección del representante, en tanto que implica la satisfacción del procedimiento estatuido en la ley, el de la elección; de hecho, podría decirse que todos los elegidos gozan, en un alto grado, de una estructura política que le garantiza unos votos, estructuras que no son cosa diferente a redes clientelares, en cualquiera de sus clases, bien sea a partir de ejercicios de patronazgo político, bien por transacción con líderes comunitarios o bien por compra de votos, y de alguna manera esas estructuras, conocidas popularmente como maquinarias, se encuentran justificadas ante la opinión pública por formar parte de la "tradición" política. Ahora bien, las organizaciones políticas estructuradas sobre la base de relaciones clientelares necesitan asegurar su subsistencia a partir de mantener y profundizar esas relaciones, dado que, de otra forma, se les hace más difícil la garantía del número mínimo de votos requerido para alcanzar el umbral exigido por la normatividad colombiana, para obtener la curul y conservar la personería jurídica del partido o movimiento político ${ }^{86}$.

de los actores del conflicto, al respecto ver: Rangel, Alfredo; Borrero, Armando y Ramírez, William, Conflictividad territorial en Colombia, ESAP-Fundación Buen Gobierno, Bogotá D.C., 2004.

${ }^{84}$ Audelo Cruz, Jorge M., "¿Qué es clientelismo? Algunas claves para comprender la política en los países en vías de consolidación democrática", Revista Estudios Sociales, vol. 12, № 24, julio-diciembre, CIAD, AC, Sonora, 2004. En: http://redalyc.uaemex. mx/src/inicio/ArtPdfRed.jsp?iCve=41702404 [visitado el 13/12/2012].

${ }^{85}$ ACuÑa Chaverri, "Elementos conceptuales", cit. nota n. 80, p. 32.

${ }^{86}$ En Colombia el artículo 107 de la Constitución Política fue objeto de reforma, en dos ocasiones, por los actos legislativos 01 de 2003 y 01 de 2009, los cuales son conocidos popularmente como "reformas políticas", las cuales se estructuraron como una contrarreforma de la propia Constitución Política de 1991, con el fin de consolidar partidos políticos más fuertes, como una forma de revertir el fenómeno de hiperfragmentación política colombiana, mediante el cual se dio, durante la década de 
Así las cosas, para mantener esas redes clientelares que sustentan a la organización se acude a prácticas de corrupción, como la apropiación de recursos públicos y el tráfico de influencias, por mencionar sólo dos de las más frecuentes, de tal suerte que con la primera, la apropiación de recursos públicos, se garantiza el mantenimiento del statu quo socioeconómico del mercado electoral en prácticas como la compra de votos, ya que si esos clientes logran un ascenso social se pueden presentar dos situaciones: o se encarece el voto o desertan de la red clientelar, lo que obliga a conseguir nuevos clientes. La segunda práctica enunciada, el tráfico de influencias, está orientada al establecimiento de redes clientelares de patronazgo político, a partir de la asignación de las Ilamadas cuotas burocráticas, la cual también genera lealtades, además de favores.

La simbiosis clientelismo-corrupción esbozada en líneas anteriores permite que opere el fenómeno de $\mathrm{CdE}$ en ciertas instituciones, en donde lo público se pone al servicio de los intereses particulares del grupo o grupos captores. Esa CdE, a su vez, resulta en un fenómeno deslegitimante del Estado Social de Derecho, ya que la entidad capturada, junto con todo el tinglado que compone la estructura del Estado colombiano, debe orientar el sentido de sus actuaciones hacia el cumplimiento de los fines esenciales del Estado definidos por la dogmática constitucional, cosa que no podrá hacer si su accionar, por el contrario, está destinado a la satisfacción de los intereses particulares, incluyendo la depredación de recursos, situación que mina la inversión pública, no permitiendo, de esta forma, la toma de acciones encaminadas hacia la satisfacción de esos cometidos estatales. Esta situación de corrupción y CdE por actores ilegales es la que obliga a Felipe Botero ${ }^{87}$ a preguntarse si Colombia es una paracracia o una desgracia.

\section{Los efectos de la captura de estado en el Estado Social de Derecho}

El constituyente colombiano del año 1991 adoptó el modelo de Estado Social de Derecho como piedra angular del nuevo diseño constitucional, por ello lo concibió más que como un modelo estatal, como una cláusula general que atraviesa perpendicularmente todo el texto superior ${ }^{88}$, de tal suerte que

1990, una explosión de denominaciones políticas denominadas por algunos microempresas electorales, o como simples "marbetes" para el otorgamiento de avales. Este fenómeno es descrito ampliamente por el profesor Francisco Gutiérrez Sanín en Gutiérrez Sanín, Francisco, ¿Lo que el viento se llevó? Los partidos políticos y la democracia en Colombia (1958-2002), Grupo Editorial Norma, Bogotá D.C., 2006, pp. 301-341.

${ }^{87}$ Botero, Felipe, "Colombia: ¿democracia, paracracia o simplemente desgracia?", Revista de Ciencia Política, vol. 27, Nº especial, Pontificia Universidad Católica de Chile, Santiago de Chile, 2007. En: http://www. scielo.cl/scielo.php?pid=S0718-090X2007000100006\&script=sci_arttext [visitado el 25/11/2012].

${ }^{88} \mathrm{El}$ concepto de Estado Social de Derecho es polisémico, y a él se atribuyen multiplicidad de contenidos, por eso la tarea de conceptualizarlo resulta bastante compleja, además de que la tarea definitoria del alcance del mismo le correspondió a la Corte Constitucional colombiana, en ejercicio de su atribución 
todos los principios y reglas que lo componen se encuentren en consonancia con dicha cláusula. El Estado Social de Derecho implica el cumplimiento de los fines esenciales del Estado ${ }^{89}$ en búsqueda del bienestar general para los asociados, a partir de la satisfacción de sus necesidades mínimas, priorizando el interés general sobre el particular, teniendo de fondo el marco del respeto por los derechos y garantías constitucionales ${ }^{90}$.

La Corte Constitucional colombiana cifró el objeto del Estado Social de Derecho en las personas, razón por la cual debe tener un papel activo en la consecución de los fines señalados ${ }^{91}$, más que pasivo de simple gendarme de las libertades ${ }^{92}$. Esto implica un cambio en el rol en la administración pública,

como guardiana de la Constitución, por tal razón, la Corte suele referirse al Estado Social de Derecho de pluralidad de formas y con multiplicidad de contenidos. La tarea de sistematizar las diferentes posturas de la Corte en cuanto a la definición del alcance del Estado Social la realizó Juan Carlos Upegui mediante un ejercicio hermenéutico en el que encontró doce tesis que, a su juicio, corresponden a los ejes sobre los cuales ha gravitado la jurisprudencia constitucional, desde el año de 1992, en torno al concepto y alcance del Estado Social de Derecho. Ver: UpeGul, Juan Carlos, Doce tesis en torno al concepto de Estado social de derecho, Universidad Externado de Colombia, Bogotá D.C., 2009.

${ }^{89}$ Los fines esenciales del Estado aparecen formulados de forma taxativa en el artículo $2^{\circ}$ de la Constitución Política de Colombia. Se debe tener presente estos fines funcionan como cláusulas abiertas que funcionan como bases estructurales de la teleología constitucional. Por ello, se debe tener presente que "la razón de ser, la legitimidad y la misma validez del Estado se encuentran explícitamente formuladas en la Constitución de la cual derivan también su juridicidad y los lineamientos de su actividad. Es así como en la carta política se señalan como fines esenciales, como fines sociales y como objetivo fundamental de la actividad del Estado". Rodríguez OrtegA, La Legitimidad, cit. nota n. 4, p. 35.

${ }^{90}$ La definición de Rodríguez Ortega reúne la mayoría de elementos de lo que se suele señalar como Estado Social de Derecho: "Se entiende por Estado Social el ordenamiento político que atribuye al poder del Estado fines estrictamente sociales orientados a la eficaz prestación de los servicios públicos y a la satisfacción de las necesidades fundamentales de la población que se materializan en el BIENESTAR GENERAL y en el mejoramiento de la calidad de vida de todos los ciudadanos, de tal forma que el interés social, o interés general tenga prevalencia sobre el interés particular, en la búsqueda de la convivencia y de la justicia social". Rodríguez Ortega, La Legitimidad, cit. nota n. 4, p. 35.

91 "De esta forma, vale la pena insistir diciendo que el principio de Estado social de derecho contrasta con el Estado de derecho liberal en cuanto a sus fines: el Estado social de derecho ya no se limita solamente a asegurar la vida, la propiedad y la libertad mediante la protección contra el fraude, el hurto, el incumplimiento contractual o los daños ocasionados por terceros, funciones típicas del Estado gendarme. Sus fines tienen un mayor alcance e incluyen, entre otros, promover la prosperidad general; garantizar la efectividad de los principios, derechos y deberes consagrados en la Constitución; facilitar la participación de todos en las decisiones que los afectan y en la vida económica, política, administrativa y cultural de la Nación, y asegurar la vigencia de un orden justo (art. $2^{\circ}$ de la CPC). Para ello, el Estado cuenta con facultades amplias de intervención en la economía, las cuales han de estar orientadas a lograr los fines generales del Estado y los fines especiales de la intervención económica enunciados principalmente en el artículo 334 de la Constitución". Quintero NAVAS, Gustavo, "Introducción a la estructura del Estado colombiano", en López Sterup, Henrik (Coord.), Manual de Constitución y Democracia, Volumen II. Del Estado y la protección de los derechos, Universidad de Los Andes, Bogotá D.C., 2011.

${ }_{92}$ La Corte Constitucional colombiana, en Sentencia SU-747 de 1998, M.P. Eduardo Cifuentes Muñoz, manifestó: "Con el término social se señala que la acción del Estado debe dirigirse a garantizarle a 
en tanto que "de una administración pública que garantiza libertades individuales, absteniéndose de violarla y logrando que terceros también lo hagan, se pasa a una administración pública que continúa por esta línea pero de manera instrumental para el desarrollo de su propósito principal, consistente en garantizar derechos sociales y estándares de igualdad (material) fundados en la solidaridad"93. Es por ello que uno de los elementos fundamentales del Estado Social de Derecho lo constituye la aparición de los derechos sociales o de segunda generación ${ }^{94}$, los cuales se desprenden de la voluntad popular a partir del ejercicio deliberativo entre mayorías y minorías ${ }^{95}$, lo que implica un reconocimiento a las luchas y tensiones por la inclusión social ${ }^{96}$.

En suma, del cumplimiento del objeto definido para el Estado, en el marco de la cláusula general de Estado Social de Derecho, se deriva la legitimidad en el ejercicio del poder político, tal y como lo señala la Corte Constitucional colombiana: "La legitimidad del poder del Estado y de sus instituciones políticas y jurídicas se basa en el respeto, la garantía y la promoción de los derechos fundamentales" ${ }^{\prime 97}$, y más que de los derechos fundamentales exclusivamente, de todos los principios establecidos por la dogmática consti-

los asociados condiciones de vida dignas. Es decir, con este concepto se resalta que la voluntad del Constituyente en torno al Estado no se reduce a exigir de éste que no interfiera o recorte las libertades de las personas, sino que también exige que el mismo se ponga en movimiento para contrarrestar las desigualdades sociales existentes y para ofrecerle a todos las oportunidades necesarias para desarrollar sus aptitudes y para superar los apremios materiales".

${ }^{93}$ Montaña Plata, Fundamentos, cit. nota n. 5, p. 80.

94 "El Estado que acepta e incorpora al orden jurídico, a partir de su propia Constitución, derechos sociales fundamentales junto a los clásicos derechos políticos y civiles, es conocido como Estado social. Los últimos son catalogados como derechos de primera generación, mientras que los derechos sociales se han calificados como derechos de segunda generación. Hoy se habla incluso de derechos de tercera generación". ViLLAR BORDA, Luis, "Estado de derecho y Estado social de derecho", Revista Derecho del Estado, № 20, diciembre, Universidad Externado de Colombia, Bogotá D.C., 2007, p. 86. En: http://foros.uexternado.edu.co/ecoinstitucional/index.php/derest/article/viewFile/705/667 [visitado el 04/06/2013].

${ }_{95}$ Para el constitucionalista mexicano Miguel Carbonell, "el constitucionalismo contempla a las minorías desde una triple perspectiva", a saber el ser humano individual, como la minoría esencial e irreductible, la cual protege a partir del respeto por los derechos humanos, en segunda medida se encuentran las minorías políticas, a las cuales se les debe garantizar un estatus mínimo y las condiciones de participación, y la tercera corresponde a las minorías étnicas o culturales, en donde entrarían aspectos diferenciadores de la mayoría racial o cultural del Estado. Ver: CARBOnelL, Miguel, Elementos de derecho constitucional, Fontamara, México, 2004, p. 37.

${ }^{96}$ Ver: Quintero Mosquera, Diana Patricia, "El Estado social de derecho como categoría política y jurídica", en Silva Vega, Rafael, Milanese; Juan Pablo y Rouvinskı, Vladimir (Comp. ), Desafíos para la democracia y la ciudadanía, Universidad Icesi, Cali, 2012, pp. 37-38.

${ }^{97}$ Sentencia C-573 de 2003, M.P. Jaime Córdoba Triviño, proferida por la Corte Constitucional colombiana. 
tucional ${ }^{98}$, tal y como aparece definido desde los primeros fallos de la Corte Constitucional ${ }^{99}$.

En líneas anteriores se expuso la idea de que la legitimidad en el ejercicio del poder político, diferente a la legitimidad del orden político, debe ser coherente con el objeto del Estado Social de Derecho, y para ello se distinguen dos tipos de legitimidades: una de tipo formal y una de tipo material. La mayoría de la literatura política se refiere a la del orden político, y en este sentido se emparentan con la legitimidad formal, en tanto que se pretende dar respuesta a la cuestión del porqué unos hombres libres deben obedecer a otros hombres, y su respuesta distingue a un régimen político de facto de uno de derecho ${ }^{100}$. A su vez, la legitimidad material se refiere al cumplimiento del objeto del Estado, esto es, la satisfacción de los cometidos definidos por el constituyente en su parte dogmática ${ }^{101}$. Esta legitimidad se equipara en contenidos a lo que la Corte Constitucional colombiana ha denominado como legitimidad por vía de institucionalización ${ }^{102}$. La legitimidad material implica que no sólo basta con

\footnotetext{
${ }^{98}$ Siguiendo las mismas trazas argumentales, Sierra Porto manifestó: "El Estado Constitucional colombiano fue pensado por el constituyente de 1991 como un típico Estado social de derecho, esto es, dotado de abundantes y prolíficas declaraciones de derechos y principios que nos muestran el norte o razón de ser de la actividad del Estado: en la parte inicial de la Constitución se establecieron 95 artículos dedicados a los derechos constitucionales en sus distintas variedades y clasificaciones; allí se encuentran derechos de todo tipo: derechos de autonomía, políticos y prestacionales o asistenciales y, en esta segunda variedad, derechos de segunda y tercera generación. A esta amplia regulación de la parte dogmática le correspondería una estructura estatal igualmente amplia y diseñada con el propósito y con el tamaño suficiente para dar respuesta a las aspiraciones y a las garantías del texto constitucional". SIERRA PORTO, Humberto Antonio, "La administración de justicia en el Estado social de derecho privatizado", Revista Jurídicas, vol. 5, № 1, enero-junio, Universidad de Caldas, Manizales, 2008, p. 191. En: http:// juridicas.ucaldas.edu.co/ downloads/juridicas5(1)_ 10.pdf [visitado el 04/02/2013].

${ }^{99}$ Ver: Sentencia T-406 de 1992, M.P. Ciro Angarita Barón, de la Corte Constitucional colombiana.

${ }^{100}$ Sobre este aspecto la Corte Constitucional de Colombia, en Sentencia C-522 de 2002, M.P. Jaime Córdoba Triviño, indicó: "Dentro de los aspectos que se consideran centrales en los análisis sobre el poder político y su ejercicio, se encuentra lo relativo a la justificación del poder. Responder a la pregunta de por qué unos mandan y por qué otros deben obedecer distingue la existencia de un régimen político de facto de uno de derecho. La voluntad popular como única fuente de legitimidad del poder político resulta del reconocimiento de la libertad e igualdad como atributos de la condición humana que deben garantizarse en la vida colectiva".

101 Sobre este aspecto ver la Sentencia T-772 de 2003, de la Corte Constitucional colombiana, M.P. Manuel José Cepeda Espinosa, en donde se cifra el alcance del Estado Social de Derecho: "se trata de un principio cardinal de nuestro ordenamiento constitucional, que le imprime un sentido, un carácter y unos objetivos específicos a la organización estatal en su conjunto, y que resulta -en consecuencia- vinculante para las autoridades, quienes deberán guiar su actuación hacia el logro de los cometidos particulares propios de tal sistema: la promoción de condiciones de vida dignas para todas las personas, y la solución de las desigualdades reales que se presentan en la sociedad, con miras a instaurar un orden justo".

102 Ver: Sentencia C-292 de 2003, M.P. Eduardo Montealegre Lynnet, de la Corte Constitucional colombiana.
} 
resultar elegido a través de un procedimiento democrático, sino que se requiere que el mandato entregado por los electores desarrolle un cumplimiento efectivo de sus funciones, pero atendiendo a que esa gestión debe estar orientada siempre hacia la satisfacción de los fines esenciales del Estado definidos por el constituyente y que se desprenden de los contenidos de la cláusula general de Estado Social de Derecho. Montaña Plata señaló al respecto: "La presencia de una Constitución Política de la que se derivan los fines del estado, es entonces presupuesto de existencia de la función administrativa; y la forma de estado y las características principales de éste, constituyen un argumento de forzosa revisión para los fines de materializar y actuar un concepto de función administrativa como el que se propone desde esta óptica"103.

El concepto de legitimidad material en el Estado Social de Derecho implica que si un representante fue elegido democráticamente, pero sus actuaciones se encuentran orientadas en un sentido diferente al cumplimiento de los fines del Estado, atendiendo a intereses particulares discordantes del interés público, ese ejercicio del poder político carecerá de legitimidad, en el sentido material, aun cuando en apariencia esté revestido de legitimidad formal. Por ello, cuando ocurre el fenómeno de captura de Estado (CdE) en alguna entidad pública, aparece un menoscabo a la legitimidad material, puesto que la entidad o institución capturada dejará de orientar su quehacer administrativo hacia el cumplimiento de los fines del Estado, para orientarlo hacia la satisfacción de los intereses particulares de los agentes captores, sin importar que éstos sean de naturaleza legal o ilegal. Esto no quiere decir que la satisfacción de todos los intereses particulares impliquen una deslegitimación material, puesto que ello no sería coherente con el propio texto superior que también protege los derechos e intereses individuales ${ }^{104}$, lo que se quiere decir es que los intereses particulares que sean contrarios a la teleología constitucional no pueden sustituir la preservación del interés general o de los intereses individuales que cifran su asidero en la dogmática superior ${ }^{105}$.

${ }^{103}$ Montaña Plata, Fundamentos, cit. nota n. 5, p. 89.

${ }^{104}$ La Sentencia C-539 de 1999, M.P. Eduardo Cifuentes Muñoz, de la Corte Constitucional colombiana, expone en lo tocante: "La prevalencia del interés general -en aquellos casos en los cuales se demuestre que en efecto existe un verdadero interés general- no es un principio constitucional de carácter absoluto. Ciertamente, dicho principio puede resultar enfrentado a derechos e intereses de carácter eminentemente individual, igualmente protegidos por la Constitución e, incluso, a derechos que, como los derechos inalienables de la persona humana o los derechos de los niños tienen primacía en el orden jurídico, por expreso mandato constitucional. En caso de presentarse un conflicto de esta índole, el interés general en cuestión debe ser armonizado con el derecho o interés individual con el que choca, a fin de encontrar una solución que, a la luz de las particularidades del caso concreto, maximice ambos extremos de la tensión".

105 Al respecto ver la Sentencia T-520 de 2003, M.P. Rodrigo Escobar Gil, de la Corte Constitucional colombiana: "El Estado social no pretende la transformación radical de las estructuras sociales, sino 
Efectivamente, en este punto se debe hacer referencia a la dicotomía presente entre lo público y lo privado ${ }^{106}$, lo cual implica relaciones antípodas en cuanto a lo pretendido por los sujetos que se traban en la relación objeto de análisis, por ejemplo, en materia de propiedad "Io público está abierto a la pertenencia de todos con base en el principio jurisdiccional de la inclusión. En tanto que lo privado se basa en el referente antípoda. Aquello privado (he ahí la genealogía etimológica del término) significa una privación, vale decir una exclusión, una abstinencia. Con lo cual el término privado se define por una vía negativa, mientras que el otro, lo público, se construye en una perspectiva positiva, de afirmación. Pero al mismo tiempo el término privado posee el sentido positivo del disfrute continuado y asegurado de la posesión indefinida que les es negado a los demás"107. Las valoraciones entre lo público y lo privado dependen de los acuerdos colectivos a los que se llega en el ejercicio de la deliberación en los sistemas democráticos ${ }^{108}$, lo que incluye el reconocimiento de los derechos de las minorías y su salvaguarda dentro del paradigma de Estado Constitucional ${ }^{109}$, luego, entonces, si bien es cierto que el interés público aparece como un concepto jurídico indeterminado, también lo es que la dificultad teórica para la delimitación de tales acuerdos ${ }^{110}$ obliga a que la definición de los contenidos de éstos recaiga en el ejercicio hermenéutico que del texto constitucional hace la Corte Constitucional, quien, en su condición de guardiana de la Constitución ${ }^{111}$

la corrección sistemática de sus consecuencias más graves, y la promoción de sus efectos deseables. Asimismo, el Estado social permite la interacción de los agentes sociales, sin querer determinar sus relaciones por intermedio del Estado. Por el contrario, permite su libre juego, dentro de un marco que garantice la convivencia social presente y futura, tomando la dignidad humana como elemento indispensable para la continuidad de cualquier comunidad política. En ese orden de ideas, puede afirmarse que los deberes constitucionales son instrumentos jurídicos que garantizan que los particulares cumplan sus funciones dentro de la sociedad para lograr determinados objetivos constitucionales, sin necesidad de estructurar las relaciones entre los agentes sociales a través del Estado".

${ }^{106}$ El inciso $1^{\circ}$ del artículo 58 de la Constitución Política consagra la prevalencia del interés público frente al privado, en caso en que éstos Ilegaren a colisionar. Este principio constitucional, a su vez, se encuentra orientado por el valor constitucional de primacía del interés general que está consagrado en el artículo $1^{\circ}$ de la misma carta superior.

${ }^{107}$ Varela Barrios, Edgar, Desafíos del interés público. Identidades y diferencias entre lo público y lo privado, Universidad del Valle, Cali, 2005, p. 21.

108 "Según las épocas y los lugares, aquellos proyectos colectivos estuvieron dominados por la lucha contra las tradiciones, por el nacionalismo o por los afanes de la expansión imperialista. Pero muy claramente, desde la década del cuarenta -después de años de depresión económica, de desempleo masivo y de guerra- el crecimiento industrial, la ocupación plena y la prosperidad se instalaron como los ideales sustantivos por excelencia". Nun, José, Democracia, cit. nota. n. 47, p. 98.

${ }^{109}$ Ver: Rodríguez Peñaranda, María Luisa, Minorías, acción pública de inconstitucionalidad y democracia deliberativa, Universidad Externado de Colombia, Bogotá D.C., 2005.

110 Ver: Varela Barrios, Edgar, Desafíos, cit. nota n. 107, pp. 30-34.

111 Artículo 241 de la Constitución Política. 
está obligada a proteger el valor constitucional del interés general, el cual, por ser una cláusula de textura abierta, debe concretarse en cada caso, por ello la tarea definitoria de contenidos por parte del tribunal constitucional resulta fundamental para la orientación del aparato estatal, de los fines esenciales hacia donde debe orientarse su quehacer. En este sentido, se puede concluir que los valores y principios constitucionales, con los contenidos de los que los dota la Corte Constitucional colombiana, constituyen los acuerdos generales que permiten orientar la concreción y limitaciones del actuar del interés particular sin que afecte el interés público, los cuales se reflejan, principalmente, en los primeros diez artículos de la carta política.

Se debe tener presente que el interés privado resulta en una garantía superior heredada del paradigma liberal, la cual deberá respetar, y no confrontar con el interés público ${ }^{112}$, el cual depende, a su vez, de los contenidos entregados por la Corte Constitucional a los principios derivados de la Constitución, incluyendo los innominados, los cuales son reconocidos por el artículo 94 de la misma. Luego, entonces, resulta deducible que cuando el interés privado supera al público, y en una colisión entre ellos el segundo resulta con una posición ventajosa frente al primero, se puede estar en presencia de un fenómeno deslegitimador del Estado Social de Derecho, desde el punto de vista material, inclusive, frente a un fenómeno de $\mathrm{CdE}$, en donde el interés particular a ponderar por sobre el público corresponderá al que detenten los agentes captores.

La CdE produce un efecto directo en la legitimidad material en el ejercicio del poder en el Estado Social de Derecho, no sólo para la institución capturada, sino para todo el Estado, ya que no puede existir una legitimidad parcial o una deslegitimación parcial, puesto que las consecuencias de mantenimiento de pobreza, depredación de recursos públicos y primacía de los intereses particulares de los captores por sobre el interés público, hacen que no se pueda avanzar en la satisfacción de los fines esenciales definidos por la dogmática constitucional, de tal suerte que, verbigracia, un municipio capturado hace que todo el Estado Social de Derecho carezca de legitimidad, por cuanto los habitantes de ese municipio no se puedan acercar a lo que la teleología constitucional definió para ellos, como asociados a ese Estado Social de Derecho. Así las cosas la CdE no se puede entender como un paso previo para que se constituya la ilegitimidad material en el ejercicio del poder político en el Estado Social de Derecho, pero

\footnotetext{
112 Prueba de ello la constituye el otorgamiento de una función social y ecológica a la propiedad privada, por parte del constituyente de 1991, tal y como aparece en el inciso $2^{\circ}$ del artículo 58 de la Constitución Política. Sobre este aspecto la Corte Constitucional, en Sentencia C-666 de 2010, M.P. Humberto Antonio Sierra Porto, señaló: "La función social de la propiedad se incorpora al contenido de ella para imponer al titular del dominio obligaciones en beneficio de la sociedad. En otros términos, el contenido social de las obligaciones limita internamente el contenido individual de facultades o poderes del propietario, según la concepción duguitiana de la propiedad función".
} 
sí aparece como un factor configurante de esa ilegitimidad, es decir, siempre que hay $\mathrm{CdE}$, y mucho más cuando se presenta la $\mathrm{RCdE}$, se está en presencia de un fenómeno deslegitimante, en tanto que el aparato estatal no está orientado a hacer lo que debería, de acuerdo con la teleología constitucional, sino que su quehacer está orientado hacia donde lo orienten los agentes captores.

Este análisis en un medio como el colombiano, que frecuentemente se encuentra impactado por escándalos sucesivos de corrupción, puede resultar agobiante, lo que significaría, que la legitimidad material en el ejercicio del poder político no es más que una utopía imposible de alcanzar; por el contrario, su ubicación en el plano deontológico conlleva a que se trata de una cláusula orientadora hacia el deber ser, el punto de llegada, mas no necesariamente el punto de partida.

\section{CONCLUSIÓN}

El texto se encuentra elaborado desde el punto de encuentro existente entre el derecho constitucional y la ciencia política. Los análisis de la legitimidad suelen darse bien desde la dogmática jurídica pura, lo que hace un análisis muy descriptivo, o bien desde la teoría política, lo que hace que el análisis se centre en la legitimidad del orden político, pero no es muy frecuente encontrar análisis que se realicen desde un diálogo de saberes entre la política y el derecho, particularmente el constitucional, y ese es uno de los propósitos del trabajo, por ello la legitimidad política que se estudia no es la del orden político sino la que se presenta en el ejercicio del poder político, aunque para llegar a ese punto se comienza por hacer una breve aproximación a la legitimidad del orden políti$\mathrm{CO}$, a partir de autores como Ferrero, Weber y Habermas. La intersección entre política y derecho constitucional parte de la revisión de la legitimidad dentro del modelo de Estado definido por el constituyente, pero haciendo una revisión no del ordenamiento que se desprende después del hito constitucional, sino del ejercicio del poder en las instituciones que se desprenden de ese hito, por ello la legitimidad en el ejercicio del poder político, que en últimas termina siendo un análisis del cumplimiento del objeto de esa institucionalidad pública a la luz del modelo de Estado Social de Derecho, se explica a través de la diferenciación propuesta entre legitimidad formal y legitimidad material, que funciona dentro de los referentes mencionados: frontera entre el derecho constitucional y la ciencia política, análisis a la luz del ejercicio del poder político y el telón de fondo que es la cláusula constitucional de Estado Social de Derecho.

Así las cosas el quid de la cuestión radica en evidenciar cómo la satisfacción del objeto otorgado al Estado, cual es el cumplimiento de sus fines esenciales, corresponde, a su vez, con la fuente de legitimidad en el ejercicio del poder político, en el tipo de legitimidad que aquí se denomina material, lo cual permite una nueva clave explicativa a fenómenos como la corrupción, el clientelismo o 
la captura de Estado, que vistos desde el prisma de la legitimidad, encuentran la mejor forma para explicar su impacto en el modelo de Estado escogido por el constituyente colombiano: el Estado Social de Derecho.

Ello resulta relevante en la medida en que se permite analizar al Estado Social de Derecho no como un principio constitucional abstracto y con una tarea definitoria exclusiva de la Corte Constitucional, sino como el vehículo articulador de la teleología constitucional con la arquitectura del aparato estatal, con el fin de facilitar la tarea hermenéutica de comprender las racionalidades subyacentes en la toma de decisiones, en aras de determinar la concreción de fenómenos como la CdE y su impacto en la legitimidad en el ejercicio del poder político, no sólo desde un punto de vista formal, sino también, y tal vez más importante para la deliberación pública, desde un punto de vista material.

\section{Bibliografía CitADA}

\section{Artículos académicos}

ACUÑA CHAVERRI, Iván Anselmo, "Elementos conceptuales del clientelismo político y sus repercusiones en la democracia", Revista Reflexiones, vol. 2, № 88, Universidad de Costa Rica, San José, 2009. En: http://www.reflexiones.fcs. ucr.ac.cr/images/edicion_88_2_09/clientelismoPoliticoRepercusionesDemocracia.pdf [visitado el 10/12/2012].

Audelo Cruz, Jorge M., “¿Qué es clientelismo? Algunas claves para comprender la política en los países en vías de consolidación democrática", Revista Estudios Sociales, vol. 12, No 24, julio-diciembre, CIAD, AC, Sonora, 2004. En: http://redalyc.uaemex.mx/src/inicio/ArtPdfRed.jsp?iCve=41702404 [visitado el 13/12/2012].

Arráez, Morella, Calles, Josefina y Moreno de Tovar, Liuval, "La Hermenéutica: una actividad interpretativa", Revista Sapiens, vol. 7, № 2, diciembre, Universidad Pedagógica Experimental Libertador, Caracas, 2006. En: http:// www.redalyc.org/articulo.oa?id=41070212 [visitado el 02/08/2013].

Artavia Araya, Fernando, "Decisiones públicas, beneficios privados. Consideraciones teóricas en torno a la corrupción", Revista de Ciencias Sociales, vol. I, № 119, Universidad de Costa Rica, San José, 2008. En: http://163.178.170.74/wp-content/revistas/119/01-Artavia-Decisiones\%20 P\%C3\%BAblicas.pdf [visitado el 29/01/2013].

Botero, Felipe, "Colombia: ¿democracia, paracracia o simplemente desgracia?", Revista de Ciencia Política, vol. 27, No especial, Pontificia Universidad Católica de Chile, Santiago de Chile, 2007. En: http://www.scielo.cl/scielo.php?pid=S0718-090X20070001 00006\&script=sci_arttext [visitado el 25/11/2012]. 
Cazzola, Franco, "Conceptualizando la corrupción", Revista Metapolítica, № 45, enero-febrero, Centro de Estudios de Política Comparada, México, 2006.

CEa Egaña, José Luis, "Sobre el Estado constitucional de derecho como paradigma jurídico", Revista de Derecho, V. 16, julio, Universidad Austral de Chile, Valdivia, 2004. En: http://www.scielo.cl/scielo.php?script=sci_arttext\&pid=S071809502004000100020\&lng=es\&nrm=iso\&tlng=es[visitado el 03/08/2013].

Cendales, Andrés, "¿Son los pobres las únicas víctimas con la compra de votos? Un caso de competencia política con expropiación generalizada", Revista Cuadernos de Economía, vol. 31, № 56, Universidad Nacional de Colombia, Bogotá D.C., 2012.

Della Porta, Donatella, "Partidos políticos y corrupción. Reflexiones sobre el caso italiano", Revista Nueva Sociedad, No 145, septiembre-octubre, Fundación Friedrich Ebert, Buenos Aires, 1996. En: http://nuso.org/upload/ articulos/2535_1.pdf [visitado el 17/01/2013].

Della Porta, Donatella y Mény, Yves, "Democracia y Corrupción", Revista Metapolítica, № 45, enero-febrero, Centro de Estudios de Política Comparada, México, 2006.

López, Claudia y Sevillano, Óscar, "Balance político de la parapolítica", Revista Arcanos, № 14, diciembre, Corporación Nuevo Arco Iris, Bogotá D.C., 2008. En: http://www.arcoiris.com.co/wp-content/uploads/2011/arcanos/ revista_ARCANOS_14.pdf [visitado el 22/11/2012].

López Hernández, José, "El concepto de legitimidad en perspectiva histórica", Cuadernos Electrónicos de Filosofía del Derecho, № 18, Instituto de Derechos Humanos de la Universidad de Valencia, Valencia, 2009. En: http://ojs. uv.es/index.php/ CEFD/article/view/116/124 [visitado el 18/11/2012].

Martínez Ferro, Hernán, "Legitimidad, dominación y derecho en la teoría sociológica del Estado de Max Weber", Revista Estudios Socio-Jurídicos, vol. 12, № 1, enero-junio, Universidad del Rosario, Bogotá D.C., 2010.

, "Los principios de la legitimidad política (Ferrero y los genios invisibles de la ciudad)", Revista Diálogos de Saberes, No 31, julio-diciembre, Universidad Libre de Colombia, Bogotá D.C., 2009.

Ortega, Onasis, "Dos caras de la filosofía política contemporánea", Revista Praxis Filosófica, Nueva serie, № 25, julio-diciembre, Universidad del Valle, Cali, 2007.

Saíz Vélez, Jorge Enrique, Mantilla Bautista, Sergio Iván y Cárdenas Beltrán, Jesús María, "Efectos de la corrupción sobre la criminalidad, el crecimiento económico y la pobreza: una evidencia para seis departamentos de Colombia", Revista Criterio Libre, vol. 10, № 16, enero-junio, Universidad Libre de Colombia, Bogotá D.C., 2012. 
SChARPF, Fritz, "Conceptos de legitimación más allá del Estado-nación", Revista Española de Ciencia Política, № 13, octubre, Asociación Española de Ciencia Política y de la Administración, Madrid, 2005.

SCHRÖTER, Bárbara, "Clientelismo político: ¿existe el fantasma y cómo se viste?", Revista Mexicana de Sociología, vol. 72, № 1, enero-marzo, Universidad Nacional Autónoma de México-Instituto de Investigaciones Sociales, México, 2010. En: http://www.ejournal.unam.mx/rms/20101/RMS010000105.pdf [visitado el 08/12/2012].

Sierra Porto, Humberto Antonio, "La administración de justicia en el Estado social de derecho privatizado", Revista Jurídicas, vol. 5, № 1, enero - junio, Universidad de Caldas, Manizales, 2008. En: http://juridicas.ucaldas.edu. co/ downloads/juridicas5(1)_ 10.pdf [visitado el 04/02/2013].

Vértiz Galván, Miguel Ángel, "El combate a la corrupción en los procedimientos administrativos. Una aproximación teórica", Revista Gestión y Política Pública, vol. 9, № 2, Centro de Investigación y Docencia Económicas, México, 2000, En: http://www.gestionypoliticapublica.cide.edu/num_anteriores/Vol. IX_No.II_2dosem/VGM_Vol.9_No.II_2sem.pdf [visitado el 16/01/2013].

VILLAR Borda, Luis, "Estado de derecho y Estado social de derecho", Revista Derecho del Estado, № 20, diciembre, Universidad Externado de Colombia, Bogotá D.C., 2007.En: http://foros.uexternado.edu.co/ecoinstitucional/index. php/derest/article/ viewFile/705/667 [visitado el 04/06/2013].

\section{Artículos de prensa}

"El Segundo Bogotazo", Revista Semana, edición 1615, 13 de abril de 2013. En: http://www.semana.com/nacion/articulo/el-segundo-bogotazo/339828-3 [visitado el 14/04/2013].

\section{Capítulos de libros}

CUERVO, Jorge Iván, “¿Democracia sin representación? Apuntes para una caracterización de la democracia no deliberativa", en Vela OrBegozo, Bernardo, Dilemas de la Política, Tomo I, Universidad Externado de Colombia, Bogotá D.C., 2007.

DÁVILA, Andrés y Delgado, Natalia, "La metamorfosis del sistema político colombiano: ¿clientelismo de mercado o nueva forma de intermediación", en Gutiérrez Sanín, Francisco (Comp.), Degradación o cambio. Evolución del sistema político colombiano, IEPRI-Editorial Norma, Bogotá D.C., 2002.

Del Águila, Rafael, "La política: el poder y la legitimidad", en Del Águila, Rafael (ed.), Manual de Ciencia Política, segunda edición, Trotta, Madrid, 2000. 
LÓPEZ, Claudia, "La refundación de la patria, de la teoría a la evidencia", en LóPEZ, Claudia (ed.), Y refundaron la patria... De cómo mafiosos y políticos reconfiguraron el Estado Colombiano, Random House Mondadori-Corporación Nuevo Arco Iris, Bogotá D.C., 2010.

Quintero Mosquera, Diana Patricia, "El Estado social de derecho como categoría política y jurídica", en Silva Vega, Rafael, Milanese, Juan Pablo y RouvinSKI, Vladimir (Comp.), Desafíos para la democracia y la ciudadanía, Universidad Icesi, Cali, 2012.

Quintero Navas, Gustavo, "Introducción a la estructura del Estado colombiano", en López Sterup, Henrik (Coord.), Manual de Constitución y Democracia, Volumen II. Del Estado y la protección de los derechos, Universidad de Los Andes, Bogotá D.C., 2011.

\section{Libros}

Arnoletto, Eduardo Jorge, Curso de Teoría Política, edición electrónica gratuita, 2007. En: www.eumed.net/libros/2007b/300/[visitado el 26/12/2012].

Bоввіо, Norberto, Teoría de las formas de gobierno en la historia del pensamiento político, Fondo de Cultura Económica, México, 1996. - El futuro de la democracia, Fondo de Cultura Económica, México, 1986.

Carbonell, Miguel, Elementos de derecho constitucional, Fontamara, México, 2004.

Cazorla Pérez, José, Manual de Introducción a la Ciencia Política, Fundación Núcleo de Esco, Granada, 2008. En: http://dspace.utalca.cl/bitstream/1950/9174/ 1/Texto_Completo.pdf [visitado el 02/08/2013].

Constant, Benjamín, Escritos Políticos, Centro de Estudios Constitucionales, Madrid, 1989.

FerRajolı, Luigi, Derechos y garantías. La ley del más débil, cuarta edición, Trotta, Madrid, 2004.

Ferrero, Guglielmo, El Poder. Los genios invisibles de la ciudad, Editora InterAmericana, Buenos Aires, 1943.

GadAmer, Hans-Georg, Verdad y Método, decimosegunda edición, Ediciones Sígueme, Salamanca, 2007.

Garay, Luis Jorge, Salcedo-Albarán, Eduardo, De León-Beltrán, Isaac y Guerrero, Bernardo, La captura y reconfiguración cooptada del Estado colombiano, Fundación Método-Fundación Avina-Transparencia por Colombia, Bogotá D.C., 2008.

García Villegas, Mauricio y Revelo Rebolledo, Javier Eduardo, Estado Alterado. Clientelismo, mafias y debilidad institucional en Colombia, Dejusticia, Bogotá D.C., 2010. 
García Villegas, Mauricio y Revelo Rebolledo, Javier Eduardo (Codir.), Mayorías sin democracia. Desequilibrio de poderes y Estado de derecho en Colombia, 2002-2009, Dejusticia, Bogotá D.C., 2009.

Gutiérrez Sanín, Francisco, ¿Lo que el viento se llevó? Los partidos políticos y la democracia en Colombia (1958-2002), Grupo Editorial Norma, Bogotá D.C., 2006.

Habermas, Jürgen, Facticidad y Validez. Sobre el derecho y el Estado democrático de derecho en términos de teoría del discurso, cuarta edición, Trotta, Madrid, 2005.

, Problemas de legitimación en el capitalismo tardío, Cátedra, Madrid, 1999.

, La reconstrucción del materialismo histórico, Taurus, Madrid, 1981.

Harto de Vera, Fernando, Ciencia Política y Teoría Política contemporáneas: una relación problemática, Trotta, Madrid, 2005.

HeRMET, Guy, En las fronteras de la democracia, primera edición, segunda reimpresión, Fondo de Cultura Económica, México, 1996.

Hernández Sampieri, Roberto, Fernández Collado, Carlos y Baptista lucio, María del Pilar, Metodología de la Investigación, quinta edición, McGraw-Hill, México, 2010.

KRIELE, Martin, Introducción a la Teoría del Estado, Depalma, Buenos Aires, 1980.

Membreño Cedillo, Mario, Qué se entiende por captura de Estado, Consejo Nacional Anticorrupción, Tegucigalpa, 2008.

Montaña Plata, Alberto, Fundamentos de Derecho Administrativo, Universidad Externado de Colombia, Bogotá D.C., 2010.

Nun, José, Democracia: igobierno del pueblo o gobierno de los políticos?, primera edición, tercera reimpresión, Fondo de Cultura Económica, Buenos Aires, 2002.

Rangel, Alfredo, Borrero, Armando y Ramírez, William, Conflictividad territorial en Colombia, ESAP - Fundación Buen Gobierno, Bogotá D.C., 2004.

Rodríguez Ortega, Julio Armando, La Legitimidad en el Estado Social de Derecho, Editorial Leyer, Bogotá D.C., 1998.

Rodríguez Peñaranda, María Luisa, Minorías, acción pública de inconstitucionalidad y democracia deliberativa, Universidad Externado de Colombia, Bogotá D.C., 2005.

Rosanvallon, Pierre, La legitimidad democrática: imparcialidad, reflexividad, proximidad, Manantial, Buenos Aires, 2009.

Russel, Bertrand, Power. A New Social Analysis, first edition, sixth impression, George Allen \&Unwin, London, 1948. 
Sandoval Casilimas, Carlos, Investigación Cualitativa, ICFES, Bogotá D.C., 1996.

Santofimio Gamboa, Jaime Orlando, Procedimientos administrativos y tecnología, Universidad Externado de Colombia, Bogotá D.C., 2011.

TORRES PRECIADO, Javier Fernando, Entre la participación y la exclusión: el sistema político 1848-1885, Universidad de Los Andes, Bogotá D.C., 2009.

UPEGUI, Juan Carlos, Doce tesis en torno al concepto de Estado social de derecho, Universidad Externado de Colombia, Bogotá D.C., 2009.

Varela Barrios, Edgar, Desafíos del interés público. Identidades y diferencias entre lo público y lo privado, Universidad del Valle, Cali, 2005.

Weber, Max, Economía y Sociedad I, segunda edición, segunda reimpresión, Fondo de Cultura Económica, México, 1974.

, Economía y Sociedad II, segunda edición, segunda reimpresión, Fondo de Cultura Económica, México, 1974.

\section{Normas}

Asamblea Nacional Constituyente, Constitución Política de Colombia, Gaceta Constitucional № 116 del 20 de julio de 1991.

Congreso de la República de Colombia, Acto Legislativo 01 de 2003, Diario Oficial No 45.237 de 3 de julio de 2003.

Congreso de la República de Colombia, Acto Legislativo 01 de 2009, Diario Oficial № 47.410 de 14 de julio de 2009.

\section{Jurisprudencia}

CORTE CONSTITUCIONAL, Sentencia T-908 de 2012, M.P. Nilson Pinilla Pinilla.

, Sentencia C-791 de 2011, M.P. Humberto Antonio Sierra Porto.

, Sentencia C-666 de 2010, M.P. Humberto Antonio Sierra Porto.

, Sentencia C-595 de 2010, M.P. Jorge Iván Palacio Palacio.

Sentencia T-018 de 2009, M.P. Jaime Araújo Rentería.

, Sentencia T-1094 de 2008, M.P. Clara Inés Vargas Hernández.

Sentencia C-1041 de 2007, M.P. Humberto Antonio Sierra Porto.

, Sentencia C-924 de 2007, M.P. Humberto Antonio Sierra Porto.

Sentencia C-119 de 2006, M.P. Jaime Araújo Rentería.

, Sentencia C-864 de 2004, M.P. Jaime Araújo Rentería.

Sentencia T-294 de 2004, M.P. Manuel José Cepeda Espinosa.

Sentencia T-772 de 2003, M.P. Manuel José Cepeda Espinosa.

Sentencia C-573 de 2003, M.P. Jaime Córdoba Triviño. 
, Sentencia T-520 de 2003, M.P. Rodrigo Escobar Gil.

, Sentencia C-292 de 2003, M.P. Eduardo Montealegre Lynett.

, Sentencia C-1037 de 2003, M.P. Jaime Araújo Rentería.

, Sentencia C-522 de 2002, M.P. Jaime Córdoba Triviño.

Sentencia C-1514 de 2000, M.P. Martha Victoria Sáchica Méndez.

, Sentencia C-595 de 1999, M.P. Carlos Gaviria Díaz.

, Sentencia C-539 de 1999, M.P. Eduardo Cifuentes Muñoz.

, Sentencia SU-747 de 1998, M.P. Eduardo Cifuentes Muñoz.

, Sentencia C-126 de 1998, M.P. Alejandro Martínez Caballero.

, Sentencia SU-111 de 1997, M.P. Eduardo Cifuentes Muñoz.

, Sentencia C-048 de 1997, M.P. Hernando Herrera Vergara.

, Sentencia C-566 de 1995, M.P. Eduardo Cifuentes Muñoz.

, Sentencia T-477 de 1995, M.P. Alejandro Martínez Caballero.

, Sentencia T-217 de 1994, M.P. Alejandro Martínez Caballero.

, Sentencia C-145 de 1994, M.P. Alejandro Martínez Caballero.

, Sentencia C-089 de 1994, M.P. Eduardo Cifuentes Muñoz.

, Sentencia T-598 de 1993, M.P. Eduardo Cifuentes Muñoz.

, Sentencia T-406 de 1992, M.P. Ciro Angarita Barón.

, Sentencia C-004 de 1992, M.P. Eduardo Cifuentes Muñoz.

\section{Ponencias y conferencias}

Cendales, Andrés y Jiménez, Alfi, "The dark side of clientelism", ponencia presentada en The 24th Stony Brook Game Theory Festival of the Game Theory Society, july 8-12, Stony Brook University, New York, 2013. En: http://www. gtcenter.org/ Downloads/Conf/Andres\%20Cendales1600.pdf [visitado el 19/08/2013].

Volintiru, Clara, "Clientelism and democratic accountability", conferencia dictada en Political Studies Association Graduate Network Conference, december, Newcastle, England, 2010. En: http://www.sar.org.ro/wpcontent/ uploads/ 2012/01/Clientelism-and-Democratic-Accountability.pdf [visitado el 17/08/2013]. 